\title{
Analysis of Magnetic Measurement Data by Least Squares Fit to Series Expansion Solution of 3-D Laplace Equation*
}

\author{
L.N. Blumberg
}

March 1992

*This work was performed under the auspices of the U.S. Department of Energy. 


\section{DISCLAIMER}

This report was prepared as an account of work sponsored by an agency of the United States Government. Neither the United States Government nor any agency thereof, nor any of their employees, make any warranty, express or implied, or assumes any legal liability or responsibility for the accuracy, completeness, or usefulness of any information, apparatus, product, or process disclosed, or represents that its use would not infringe privately owned rights. Reference herein to any specific commercial product, process, or service by trade name, trademark, manufacturer, or otherwise does not necessarily constitute or imply its endorsement, recommendation, or favoring by the United States Government or any agency thereof. The views and opinions of authors expressed herein do not necessarily state or reflect those of the United States Government or any agency thereof. 


\section{DISCLAIMER}

Portions of this document may be illegible in electronic image products. Images are produced from the best available original document. 
ANALYSIS OF MAGNETIC MEASUREMENT DATA BY LEAST SQUARES FIT TO SERIES EXPANSION SOLUTION OF 3-D LAPLACE EQUATION

\author{
L. N. Blumberg \\ NATIONAL SYNCHROTRON IIGHT SOURCE \\ BROOKHAVEN NATIONAL LABORATORY \\ UPTON, NY 11973-5000
}

March 1992

\title{
SUMMARY
}

We have analysed simulated magnetic measurements data for the SXLS bending magnet in a plane perpendicular to the reference axis at the magnet midpoint $\left(\theta=90^{\circ}\right)$ by fitting the data to an expansion solution of the 3dimensional Laplace Equation in curvalinear coordinates as proposed by Brown and Servranckx. The method of Least Squares is used to evaluate the expansion coefficients and their uncertainties, and compared to results from an FFT fit of 128 simulated data points on a 12-mm radius circle about the reference axis. We find that the FFT method gives smaller coefficient uncertainties (RMS deviations) than the Least Squares method when the data are within similar areas. The Least Squares method compares more favorably when a larger number of data points (1891) are used within a rectangular area of $30-\mathrm{mm}$ vertical by $60-\mathrm{mm}$ horizontal --perhaps the largest area within the 35-mm $\times$ 75-mm vacuum chamber for which data could be obtained. For a grid with $0.5-\mathrm{mm}$ spacing within the $30 \times 60 \mathrm{~mm}$ area (7381 points) the Least Squares fit gives much smaller uncertainties than the FFT. We are therefore in the favorable position of having two methods which can determine the multipole coefficients to much better accuracy than the tolerances specified to General Dynamics. The FFT method may be preferable since it requires only one Hall probe rather than the four envisioned for the least Squares grid data. However Least Squares can attain better accuracy with fewer probe movements (less data-taking time). The time factor in acquiring the data (60 days for 200 planes per magnet for the FFT data as opposed to 22 days per magnet for the 1891 point $30-\mathrm{mm}$ X $60-\mathrm{mm}$ Least Squares grid) will likely be the determining factor in choice of method. We should further explore Least Squares analysis of a Fourier expansion of data on a circle or arc of a circle since that method gives coefficient uncertainties without need for multiple independent sets of data as needed by the FFT method.

\section{FORMULATION OF BROWN-SERVRANCKX EXPANSION AND LEAST SQUARES ANALYSIS.}

The Least Squares method is well-documented in standard texts and the present program NLLS (nonlinear least squares) has been described[1]. The present version is a straight-forward extension to the case of two independent variables and is appended. The program requires the user to specify the function to which the data are to be fitted in a subroutine CALC. The present version pertains to two-dimensional magnetic field data represented by power-series expansions for the normal and skew multipole components which satisfy the 3-dimensional Laplace Equation as summarized by Brown and Servranckx[2], hereafter referred to as BS, and discussed in a previous publication[3]. The expansion of the major component, $\mathrm{Bz}$, for the normal solution which is symmetric about the median plane $z=0$ is

$$
B z=\sum_{m=0}^{N R / 2} \sum_{n=0}^{N R-2 m} C_{2 m+1, n} x^{n} z^{2 m}
$$


where the infinite series given by BS is truncated to NR-th order and factorials have been-subsumed into the C-coefficients. A series for the other two components $\mathrm{BX}$ and $\mathrm{Bs}$ in terms of the same coefficients and their first derivatives is given by BS. It is instructive to write out the series explicitly, say to 6 -th order, as

$$
\begin{aligned}
\mathrm{Bz} & \stackrel{(N O R H)}{=} \mathrm{C}_{10}+\mathrm{C}_{11} \mathrm{x}+\mathrm{C}_{12} \mathrm{x}^{2}+\mathrm{C}_{13} \mathrm{x}^{3}+\mathrm{C}_{14} \mathrm{x}^{4}+\mathrm{C}_{15} \mathrm{x}^{5}+\mathrm{C}_{16} \mathrm{x}^{6} \\
& +\mathrm{z}^{2}\left(\mathrm{C}_{30}+\mathrm{C}_{31} \mathrm{x}+\mathrm{C}_{\left.32^{2} \mathrm{x}^{2}+\mathrm{C}_{33} \mathrm{x}^{3}+\mathrm{C}_{34} \mathrm{x}^{4}\right)}\right. \\
& +\mathrm{z}^{4}\left(\mathrm{C}_{50}+\mathrm{C}_{51} \mathrm{x}+\mathrm{C}_{52} \mathrm{x}^{2}\right)+\mathrm{z}^{6} \mathrm{C}_{70} .
\end{aligned}
$$

$\mathrm{C}_{10}$ and $\mathrm{C}_{1 /}$ are the dipole and quadrupole strengths, respectively. The sextupole component is $C_{12} x^{2}+C_{35} z^{2}$ which differs from the more familiar form of this term from the two-dimensional Laplace Equation normal solution in polar coordinates

$$
\phi_{2 D}=\sum_{n=1}^{\infty} a_{n} r^{n} \sin (n \theta) \quad \text { with } x=r \cos \theta \text { and } z=r \sin \theta
$$

which, with $\vec{B}=\nabla \phi$ leads to the expression for the vertical component

$$
\begin{aligned}
& \qquad \mathrm{Bz}=\sum_{n=1}^{\infty} \mathrm{na}_{n} \mathrm{x}^{n-1} \cos (\mathrm{n}-1) \theta . \\
& \text { dipole: } \mathrm{Bz}=\mathrm{a}_{1} \\
& \text { quadrupole: } \quad \mathrm{Bz}=2 \mathrm{a}_{2} \mathrm{x} \\
& \text { sextupole: } \quad \mathrm{Bz}=3 \mathrm{a}_{3}\left(\mathrm{x}^{2}-\mathrm{z}^{2}\right) \\
& \text { octupole: } \quad \mathrm{Bz}=4 \mathrm{a}_{4}\left(\mathrm{x}^{3}-3 \mathrm{xz} \mathrm{z}^{2}\right) \\
& \text { decapole: } \quad \mathrm{Bz}=5 \mathrm{a}_{5}\left(\mathrm{x}^{4}-6 \mathrm{x}^{2} \mathrm{z}^{2}+\mathrm{z}^{4}\right)
\end{aligned}
$$

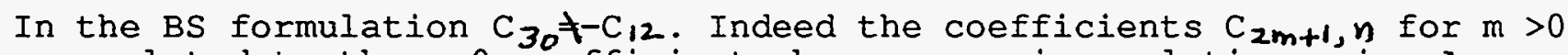
are related to the $m=0$ coefficients by a recursion relation, viz. $A_{30}=$ $-A_{10}^{\prime \prime}-A_{12}-h A_{11}$ with $A_{2 m+1, n}=n !(2 m) ! C_{2 m+1, n}, h(s)=1 / \rho(s)$ where $\rho$ (s) is the radius of curvature and $s$ is the longitudinal coordinate along the curvalinear axis, and $A_{10}^{\prime \prime}=\partial^{2} A_{10} / \partial s^{2}$. In the two-dimensional limit where $h=0$ and $A_{10}^{\prime \prime}=0$ it is readily seen that the $B S$ solution goes to the familiar 2-D multipoles. Since Eq. (1) and Eq. (4) differ, it is clear that Eq. (4) is not the correct solution for the Bz component in the plane normal to the SxLS reference axis, which we take as the axis of the curvalinear coordinate system. However, Reusch has worked out a procedure for modifying the coefficients given by a Fourier analysis of $\mathrm{Bz}$ on a circle in the transverse plane where $\mathrm{Bz}$ is a periodic function and therefore well-represented by the Fourier expansion so that the curvature-corrected coefficients correspond to the median-plane C/n coefficients of Eq. (1). Reusch has also worked out an iteration for obtaining the field components out of the median plane by the requirement that $\nabla \times \vec{B}=0$ be satisfied. This procedure should be equivalent to use of the recursion relations for the $m>0$ coefficients.

We initially felt that use of Eq. (1) was the most convenient method for obtaining the entire 3-D field without recourse to recursion relations which involve higher order longitudinal derivatives. This assumption may still be correct if one envisions further use of the mag measurements data beyond the acceptance test, such as tracking in the as-built 
machine. For the acceptance test alone, only the median plane coefficients were specified to General Dynamics (GD) and it is clear from inspection of Eq. (1) and Eq. (4) that both reduce to a simple Taylor series for $z=0$.

The 3-dimensional Laplace Equation also has a solution for which Bz is antisymmetric about the median plane, the skew multipole solution. It is

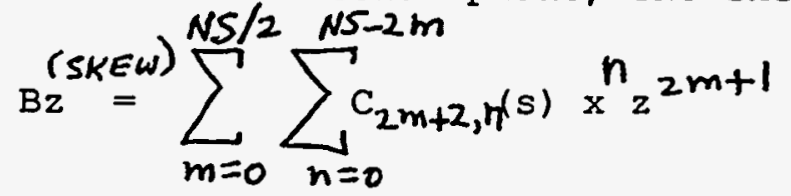

A recursion relation has also been obtained for this solution[3]. NS is the maximum order of the skew multipole for the truncated series of Eq. (5), which of course is actually an infinite series. Again, the factorials are subsumed into the c-coefficients. We write out the above series to $6-$ th order as

$$
\begin{aligned}
\text { (SKEW }) & z\left(C_{20}+C_{21} x+C_{22} x^{2}+C_{23} x^{3}+C_{24} x^{4}+C_{25} x^{5}\right) \\
& +z^{3}\left(C_{40}+C_{41} x+C_{42} x^{2}+C_{43} x^{3}\right)+z^{5}\left(C_{60}+C_{61} x\right) .
\end{aligned}
$$

Note that the skew solution has no dipole term, i.e. there are no transverse components in the median plane by definition of that plane. This agrees with the 2-dimensional skew multipoles which are obtained from the $\cos (n \theta)$ terms of the 2-D Laplace Eq. In polar coordinates,viz.

$$
\phi_{2 D}^{(S K E \omega)}=\sum_{n=1}^{\infty} b_{n} r^{n} \cos (n \theta)
$$

which leads, again from $\vec{B}=\nabla \phi$ to the 2-D skew multipoles

$$
\begin{array}{ll}
\text { dipole: } & \mathrm{Bz}=0 \\
\text { quadrupole: } & \mathrm{Bz}=-2 \mathrm{~b}_{2} \mathrm{z} \\
\text { sextupole: } & \mathrm{Bz}=-6 \mathrm{~b}_{3} \mathrm{xz} \\
\text { octupole: } & \mathrm{Bz}=-4 \mathrm{~b}_{4}\left(3 \mathrm{x}^{2} \mathrm{z}-\mathrm{z}^{3}\right) \\
\text { decapole: } & \mathrm{Bz}=-20 \mathrm{~b}_{5}\left(\mathrm{x}^{3} \mathrm{z}-\mathrm{xz}^{3}\right) \\
\text { dodecapole: } & \mathrm{Bz}=-6 \mathrm{~b}_{6}\left(5 \mathrm{x}^{4} \mathrm{z}-10 \mathrm{x}^{2} \mathrm{z}^{3}+\mathrm{z}^{5}\right) .
\end{array}
$$

Note that when compared to the 3-D solution of Eq. (6) the form of the skew solutions also differs, in this case for octupole and higher order since, in Eq. (6), $C_{22} \neq-3 C_{40}$, etc. We have included the skew series in the Least Squares fit subroutine CAIC. Presumably the skew terms can also be included in the FFT fits. The important point regarding the skew solution for our purposes is that it gives $\mathrm{Bz}=0$ in the median plane and therefore could never be determined from median plane data alone. Indeed we will need 2-D data in the plane normal to the reference axis to locate the median plane, which need not be the horizontal plane when skew terms are present. Since there are also skew resonances in the vicinity of the operating point of the SXIS, it is of importance that we know the strength of these terms in the as-built machine. We have not previously included skew terms in tracking calculations. Further, we will want to know the equilibrium orbit, the tune for small amplitude oscillations about that orbit as well as momentum-displaced closed orbits and tunes to determine the machine chromaticity and other optical 
properties. In general, the closed orbits will be deformed due to magnet and placement imperfections and will not even be in the median plane. We should perform these calculations before the machine is turned on to

have a high degree of confidence that the as-built machine will work. It is therefore essential that the complete 3-dimensional properties of the magnet be known from the mag measurements. We should also mention that, in addition to the multipole specs at the magnet center given to GD, an additional tolerance on the coil length was specified, $+/-1 / 32-i n c h$ at either end, to assure that the orbit circumference is within the $+/-500$ $\mathrm{KHz}$ spec of the RF cavity tunability. We will then have to integrate $\mathrm{Bz}$ data longitudinally along the reference axis to infer the coil length spec from the integrated dipole field and we will thus have to take data at many azimuthal points, say 100 locations as was done for the Phase I magnet per quadrant.

The Least Squares fitting procedure has been well-checked by two methods. First, we computed "exact" fields from a double precision version of TOSCA supplied by Reusch for the ideal conductor configuration of a design designated COILNOV29, and compared the Least squares fitted coefficients to those obtained by a Differential Algebra (DA) method also performed by Reusch. The DA method is essentially an evaluation of the Biot-Savart Law integral and its derivates over the conductor configuration. The second method was to generate fields given by Eq. (1) with known coefficients and then fitting that "data" with the Least Squares code NLIS. We also included skew fields from Eq. (5) in the data. In all cases the Least Squares analysis gives very reasonable results for the known coefficients. The agreement of a 14-th order fit of the TOSCA-generated data (shown in Table VI) to the DA results of the first six coefficients is quite good. A third check on the least squares program NLLS used here was to compare it to the linear least squares program LFIT published in "Numerical Recipes" [4]. Both programs gave the same results on numerous test cases.

The simulated data for the least squares fits of the BS expansion as well as the FFT fits were obtained by first generating values of the vertical component $\mathrm{Bz}$ using a special double precision version of TOSCA prepared by Reusch in the appended program MULTIPOIDP. We then added random errors to these numbers using the appended Gaussian random number generator RANGAUSS. The standard deviation of the Gaussian was somewhat arbitrarily taken as $\sigma=0.5$ Gauss. The vendor specifications [5] for the Hall probe to be used in the measurements states an accuracy of one part in 60,000 and, if this number is interpreted as an RMS error, we should use the somewhat larger value of $\sigma=0.645 \mathrm{G}$ in the $\mathrm{Bz}=3.87 \mathrm{~T}$ SXIS central field. On the other hand, if the errors are uniformly distributed in the interval $+1-0.645 \mathrm{G}$, then we are justified in using a somewhat smaller $\sigma$ for the Gaussian error approximation since it will produce errors $>1 \sigma$ in about $1 / 3$ of the cases. We are also aware that other errors will be present in the data such as knowledge of the absolute probe position and, perhaps more important, the probe temperature for which a correction will have to be applied using a probe temperature measurement of accuracy $\pm 0.1^{\circ} \mathrm{C}$ and the known temperature coefficient of the probe of $\sim 4 \mathrm{G} /{ }^{\circ} \mathrm{C}$ [5]. Moreover the probe will be in an inhomogeneous field of gradient $\sim 10 \mathrm{G} / \mathrm{mm}$ and will read some average value over its $\sim 1 \mathrm{~mm}$ diameter active area[5]. The correct error distribution for the data will have to be established experimentally by multiple independent measurements at a given point in a more uniform field than the SXIS magnet and compared to an NMR field measurement. There should be little error in reproducing the probe position since the shaft encoders for the probe holder movement will give a position accuracy of $\sim 1$-micron. For our purposes, it is important to use Gaussian errors since the parameter uncertainty calculation of Least squares assumes that the error bars are RMS values. 
To select the best fit, we typically perform fits as a function of order NR. A goodness-of-fit quantity VAR (variance) is evaluated; it is essentially the average value of $x^{2}$ for the $N$ data point ensemble, $i . e$. the mean square deviation of a data point from the fitted function, defined as

$$
\left.\operatorname{VAR}=x^{2} / \mathrm{NDF}=\sum_{j=1}^{N}\left(\frac{y_{j}-f\left(x_{j}\right)}{\sigma_{j}}\right)\right)^{2} /(N-N P)
$$

where NP is the number of free parameters and NDF is the number of degrees of freedom for the fit. Including NP essentially prevents one from using as many parameters as data points and thereby getting an exact fit--it penalizes the user for using more parameters unless they are justified by the data. We find that VAR decreases rapidly with increasing order NR until it reaches a plateau where the minimum is often ill-defined. We choose the lowest order fit on the plateau as the best fit because there is no apparent benefit in going to higher order than necessary. Indeed, the method adds additional parameters generally at the expense of reduced accuracy of the lower order parameters.

\section{RESULTS}

\section{A. One-Dimensional Least Squares Fits.}

Since the tolerance specs given to GD are for the first five medianplane multipole coefficients ( $C_{10}$ to $C_{14}$ in the BS series of Eq. (1)) at the magnet midpoint $\left(\theta=90^{\circ}\right.$, see Fig.1) it is reasonable to ask whether we can obtain these numbers from fits to data only in the median-plane $(z=0)$, i.e. Bz vs. $x$ data where $x$ is the curvalinear coordinate in the median plane normal to the reference axis as in Fig.1. A version of NLLS (nonlinear least squares) adapted to the linear case with only one independent variable was used. In Table I we show first the fits to simulated data from $x=-30 \mathrm{~mm}$ to $+30 \mathrm{~mm}$ in $\mathrm{DX}=0.5 \mathrm{~mm}$ steps (121 points). Note that the present probe holder is not capable of covering that range, but we assume that one could be designed for this interval within the $\mathrm{x}=+/-$ $37.5 \mathrm{~mm}$ vacuum chamber. The resulting octupole strength $\mathrm{C}_{13}$ overlaps the GD tolerance but is not well within the tolerance range. The decapole, $C_{14}$ coefficient is within the tolerance but the error bars $(1 \sigma)$ are somewhat larger than we would prefer, i.e. the $2 \sigma(95 \%$ confidence interval) is at the outer limit of the 1- $\sigma$ GD tolerance. On the other hand, if we push the outer limits to $x=+1-32-\mathrm{mm}$ and go to $D X=0.25-\mathrm{mm}$ steps (257 points) we are well within the tolerance range for all coefficients and could obtain better than a 3- $\sigma$ (99\%) confidence even for the decapole strength. Thus, it is possible only with median plane data to verify the tolerances specified in the acceptance test. We assume here that there is no inherent problem in taking data in steps smaller than the sensitive area (1-mm dia.) of the probe since the measured field will be an average over the sensitive area and correspond to the field at some point near the center of the probe. A third comparison was made over the interval $\mathrm{x}=+/-18-\mathrm{mm}$ with $\mathrm{DX}=0.25-\mathrm{mm}$ ( 145 points) which we believe can be attained with the present probe holder. Here the decapole coefficient $C_{14}$ overlaps the GD tolerance but the uncertainty is larger than we would prefer. Smaller step sizes, say 0.1-mm, would improve the fit but we want to keep the step size large compared to the uncertainty in absolute position of the probe center which, for normal machining tolerances, would be $\pm 0.05-\mathrm{mm}$.

\section{B.BS LEAST SQUARES COEFEICIENTS VS FFT RESULTS WITH PRESENT PROBE HOLDER}

The present probe holder, shown in Fig.3, holds four hall probes located symmetrically at $+/-6-\mathrm{mm}$ about the holder center. The quoted nominal motion capability of the probe [6] is $+/-10-\mathrm{mm}$ horizontally; thus, the data can be obtained within +/- 16-mm horizontally, and vertically we 
can attain +/- 12-mm nominal. In Table II we show a comparison in which 128 points on the circumference of a circle of radius $R=12-\mathrm{mm} \quad(0.6-\mathrm{mm}$ spacing between points) were fitted by the FFT program and a grid with a comparable number of field points (221) in a rectangular grid of spacing $\mathrm{DX}=2-\mathrm{mm}$ from $\mathrm{x}=-16 \mathrm{~mm}$ to $+16 \mathrm{~mm}$ and $\mathrm{z}=-12 \mathrm{~mm}$ to $+12 \mathrm{~mm}$ were fitted by Least Squares. It should be pointed out that the FFT fits require multiple independent sets of 128-point data. In this case we quote results from 10 sets which means 1280 data points with 1280 movements of the probe holder in order to obtain the mean values and estimates of RMS uncertain ties of the coefficients. For the grid data we require only about 56 movements of the probe holder since 4 data points are measured per probe position. The FFT results are remarkably good, with coefficient uncertainties well within the GD tolerances. We are extremely impressed with the sensitivity of the FFT since, for the decapole component of nominal strength $\mathrm{C}_{14}=44.3 \mathrm{~T} / \mathrm{m}$, the field contribution at $\mathrm{x}=12-\mathrm{mm}$ is only $\mathrm{Bz}=$ $C_{14} x^{4}=9.2$ 10-7 T. This is about $2 \%$ of the $\sigma=5$ 10-5 T RMS noise! The RMS uncertainties in the least squares fit to the BS solution are much larger and, for the octupole and decapole, larger than the GD tolerance range. The Least Squares fit is unacceptable.

In Table III we have extended the range of the grid to $x=+1-21-\mathrm{mm}$ horizontal and $z=+/-14-\mathrm{mm}$ vertical, perhaps the largest range which could be attained with the present probe holder if the engineering clearances from the probe holder to the chamber wall are reduced to zero. Also we reduced the data spacing to $\mathrm{DX}=1-\mathrm{mm}$ so that the probe sensitive area is just touching for adjacent points. This increases the number of data points to $\mathrm{N}=1247$ which is comparable to the $1280 \mathrm{pt}$. FFT, although for this grid only about 312 probe holder movements are required. The Least Squares fit has improved over the results of Table II but are still not as good as the FFT fit. The octupole and decapole uncertainties are now well within the GD tolerances, however, so the Least Squares method could adequately resolve the coefficients in this case with fewer probe movements (less data-taking time) than the FFT.

In Table IV we show a Least Squares fit with the present probe holder with data points in the nominal rectangle $x=+1-16 \mathrm{~mm}, z=+1-12 \mathrm{~mm}$ but with the point spacing of $\mathrm{DX}=0.5 \mathrm{~mm}$. (This seems fair since the $128 \mathrm{pt}$. FFT data spacing is $0.6-\mathrm{mm}$.) The resulting $\mathrm{N}=3185$ point fit again gives results worse than the 128-point FFT fit--in particular, larger error bars for the octupole and decapole coefficients and, for the decapole, larger than the GD tolerances. Again, the Least squares fit is unacceptable.

We could consider again the extreme grid range $x=+/-21 \mathrm{~mm}, z=+/-14 \mathrm{~mm}$ but reduce the point spacing to $D X=0.5-\mathrm{mm}$ to give $N=4845$ points. In Table $V$ we summarize the least Squares fits to the BS expansion for this case. The coefficient uncertainties have decreased relative to the Table III results but the decapole error is larger than for the 128-pt FFT fit. Thus the FFT still seems better. It is conceivable that we could go to a very small point spacing, say $D X=0.25 \mathrm{~mm}$ over this $+/-21$ $\mathrm{mm} \mathrm{X}+1-14 \mathrm{~mm}$ grid (19097 points, about 4775 probe holder movements). But, by the same token, we could also increase the number of FFT points to 256 on the $12-\mathrm{mm}$ radius circle $(0.3-\mathrm{mm}$ spacing) for 2560 probe movements and achieve a better FFT result also.

C. BS Least Squares Coefficients with new 4-probe Holder, 15mm Vertical, $30 \mathrm{~mm}$ Horizontal Grid.

If a new 4-probe holder is built to cover the range $x= \pm 30-\mathrm{mm}, z= \pm 15-\mathrm{mm}$, we show in Table VI the results of a Least Squares fit for $\Delta x=1-\mathrm{mm}$ spacing ( 1891 data points, about 473 probe movements). The octupole and decapole coefficient uncertainties here are distinctly better than the 10 set FFT fits, and with only $1 / 3$ of the probe movements. And of course 
we obtain the full set of 16 coefficients with the Least Squares run and thus the field representation within the $30 \mathrm{~mm} x 60 \mathrm{~mm}$ rectangle directly. This would presumably weigh the balance in favor of Least squares, but Reusch points out that, rather than data taken on a full circle, he can analyse data on arcs of circles at larger than $12 \mathrm{~mm}$ radius which would presumably give better results. So we still cannot say with certainty that a least squares fit of grid data will do better than an FFT for the same number of probe movements.

In Table VII we go one step further, an $\mathrm{x}= \pm 30-\mathrm{mm} \mathrm{x} z= \pm 15-\mathrm{mm}$ grid with $\Delta \mathrm{x}$ $=0.5-\mathrm{mm}$ spacing (7381 points, about 1846 probe movements). Here, the results for the coefficient uncertainties are much better than the 10set EFT fit. But we also have about 50\% more probe movements. At 20-sec per probe movement we would require about 10 hours to measure the complete grid, which would not be excessive for the $\theta=90$-deg plane alone but would be too long for the $\sim 200$ planes needed to map the entire magnet (86 days). We would thus have to accept the grid of Table VI (2.63 hours/plane, 22 days for the entire magnet). The 10-set FFT data, on the other hand, at 1280 probe movements per plane, 201 planes per magnet, would require $\sim 60$ days which would also be excessive. In terms of datataking time, the Least Squares 1891 point, $X= \pm 30 \mathrm{~mm}, z= \pm 15 \mathrm{~mm}$ data seems the best choice.

\section{CONCLUSIONS}

Both the 128 point FFT fits for 10 -sets of data on an $R=12 \mathrm{~mm}$ radius circle, and the Least Squares fit of the BS expansion to data on a rectangular grid of $\pm 30 \mathrm{~mm} x \pm 15 \mathrm{~mm}$ with either $\Delta x=1-\mathrm{mm}$ (1891 point) or $\Delta x=.5-$ $\mathrm{mm}$ (7381 point) are capable of sufficient accuracy to determine whether the GD magnet meets the multipole strength tolerances up to decapole. The Least Squares method may be better in that it gives better accuracy for fewer probe holder movements if a new probe holder is built.

\section{ACKNOWLEDGEMENTS}

I wish to thank J. B. Murphy for pointing out to me the elegant solution of Brown and Servranckx for the 3-D magnetostatics problem and for his estimates of the required tolerances on the multipole coefficients. I have also had numerous helpful discussions with M. F. Reusch of Grumman Aerospace Corp. on the FFT analysis method and gratefully acknowledge his making the results of that analysis available to me.

\section{REFERENCES}

[1]. L. Blumberg, NSIS Tech Note TN-240 (1984).

[2]. K. Brown and R. Servranckx, SIAC-PUB-3381 (July, 1984).

[3]. L.N. Blumberg, J. B. Murphy and M. F. Reusch, Proc. U.S. Particle Accelerator Conference, San Francisco, May 6-9, 1991. IEEE Trans. Nucl. Sci. (to be published).

[4]. Numerical Recipes, The Art of Scientific Computing, W.H. Press, B.P. Flannery, S.A. Teukolsky and W.T. Vetterling, Cambridge Univ. Press (1986), p.513

[5]. I. Solomon, private communication, 1991.

[6]. M. Shleifer, private communication, 1991. 
TABLE

$8 / 24 / 91$

Comparison of I-Dimensional least squares fits to BROWN-SERVRANCKX EXPANSION IN MEDIAN PLANE. $\theta=90^{\circ}$ COIL NOV 29
COIL NOV $29 \quad \theta=90^{\circ}$

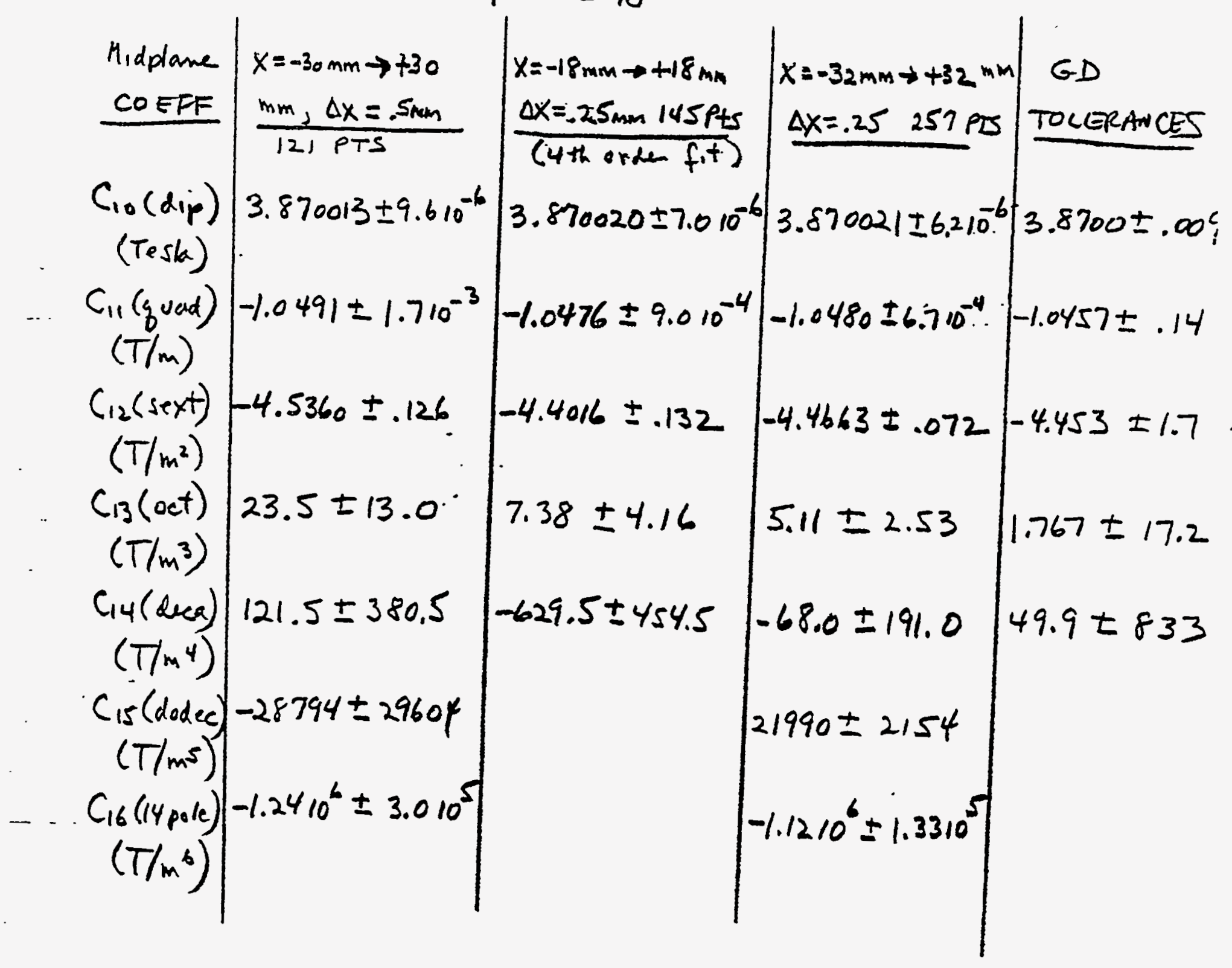

$-8-$ 
TABLE II

$8 / 2 / 91$

NOV 29 COIL

COMPARISON OF MEDIAN PLANE MULTIPOLE

COEFFICIENTS FROM GURVATURE-CORRECTED EFT

FIT AND LEAST SQUARES FIT TO POWER-SERIES IO TOSCA-GENERATED DATA WITH RANDOM ERRORS

FROM GAUSSIAN WITH STANDARD DEVIATION $=0.5$ GAUSS SIMULATED DATA ARE IN PLANE AT MAGNET CENTER ( $\left.2=90^{\circ}\right)$

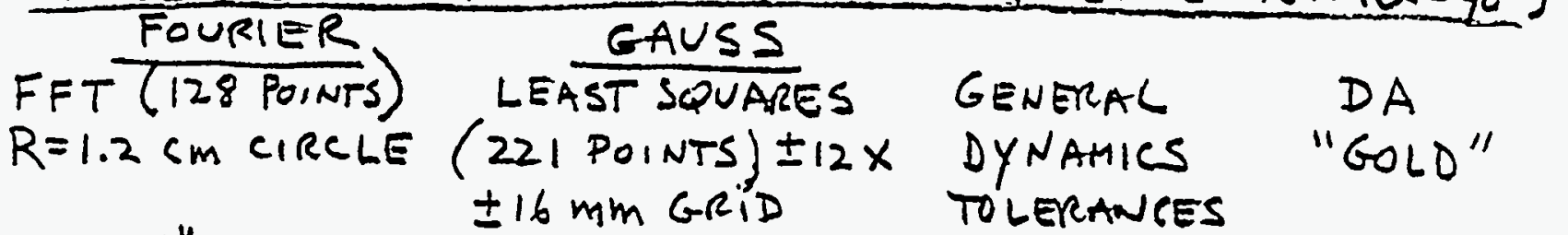
$\pm 16 \mathrm{~mm}$ GRID TOLERANCES

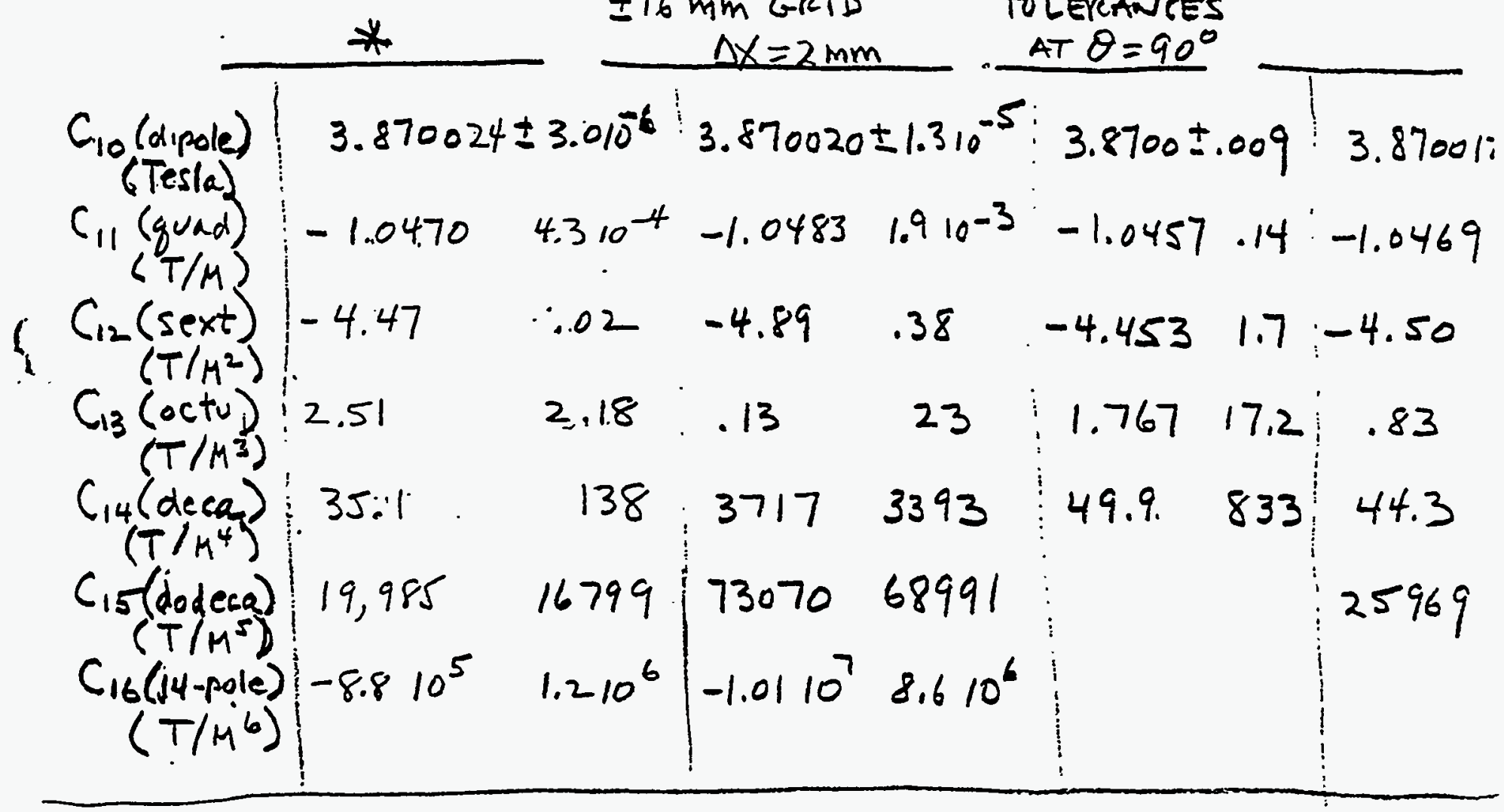

* aft mean values are from fit to yo sets of randumjzz TOSCA. DATA WITH GAUSSIAN NOISE. FOR ANALYSIS OF THE actual data, parameter uncertainties will be OBTAINED FROM MULTIPLE INDEPENDENT DATA SETS. UNCERTAINTiES ARE STANDARD DEVIATIONS.

$-9-$ 
$-10-$

TABLE III

$8 / 4 / 91$

NOV 29 COIL

$$
\theta=90^{\circ}
$$

COMPARISON OF MEDIAN -PLANE MULTIPLE COEFFICIENTS FROM CURVATURE-CORRECTED FIT FIT OF 128 TOSCA. GENERATED $B_{Z}$ VALVES ON $R=12 \mathrm{~mm}$ CIRCLE AND LEAST SQUARES FIT OF 1247 TOSCA -GENERATED $B_{Z}$ VALUES ON $\pm 14 \mathrm{~mm} X \pm 21 \mathrm{~mm}$ GRID. "DATA" RANDOMIZED IN BOTH CASES BY ADDING RANDOM NOISE FROM GAUSSIAN WITH STANDARD DEVIATION $\sigma=.56$ SIMULATED DATA ARE IN PLANE NORMAL TO SOLS REFERENCE AXIS AT MAGNET CENTER $\left(\theta=90^{\circ}, \phi=90^{\circ}\right)$ For NoV 2 9 conductor configuration.

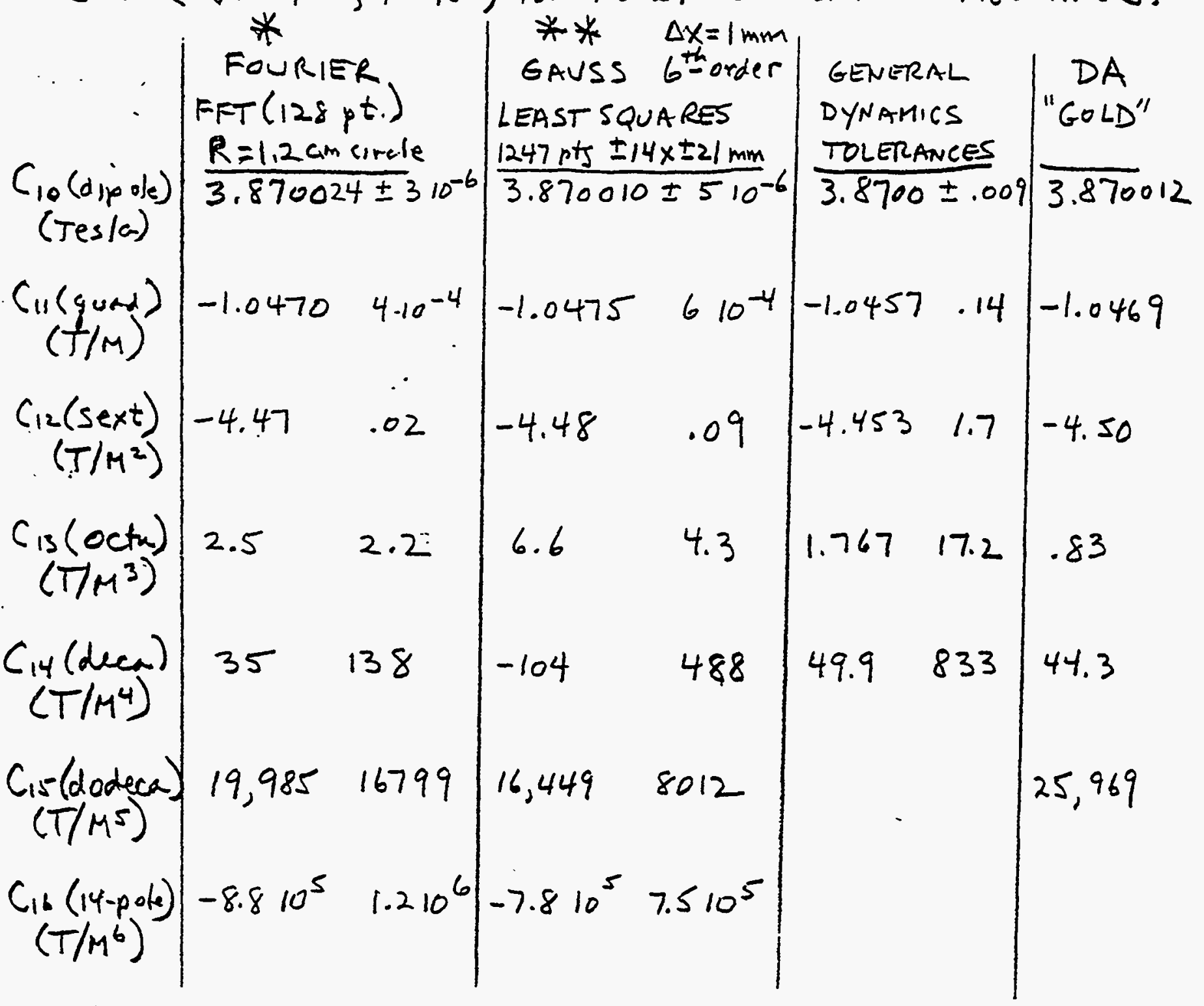

* fit mean values and rms uncertainties from 10 sets OF 128 PTS. EACH ON RANDOMIZED TOSCA DATA WITH GAUSSIAN NO ESE.

$$
\begin{aligned}
* * * B_{z}(x, z) & =C_{10}+C_{11} x+C_{12} x^{2}+C_{13} x^{3}+C_{44} x^{4}+C_{15} x^{5}+C_{16} x^{6} \\
& +z^{2}\left(C_{30}+C_{31} x+C_{32} x^{2}+C_{33} x^{3}+C_{34} x^{4}\right) \\
& +z^{4}\left(C_{50} x+C_{51} x+C_{52} x^{2}\right)+z^{6} C_{70}
\end{aligned}
$$


TABLE IV $\operatorname{collNov29\quad \theta /22/91} \theta=90^{\circ}$

COMPARISON OF 128 PT FFT RUNS (10 AND 20 SETS) WITH LEAST SQUARES FIT OF BROWN-SERVRANCKX (BS) EXPANSION ON 3185 PT. GRID, $-16 \mathrm{~mm} \leqslant x \leqslant 16 \mathrm{~mm},-12 \mathrm{~mm} \leqslant Z \leqslant 12 \mathrm{~mm}, D X=.5 \mathrm{ml}$ TOSCA DATA RANDOMIZED WITH GAUSSIAN NOISE, $\sigma=0.5$ GRUS:

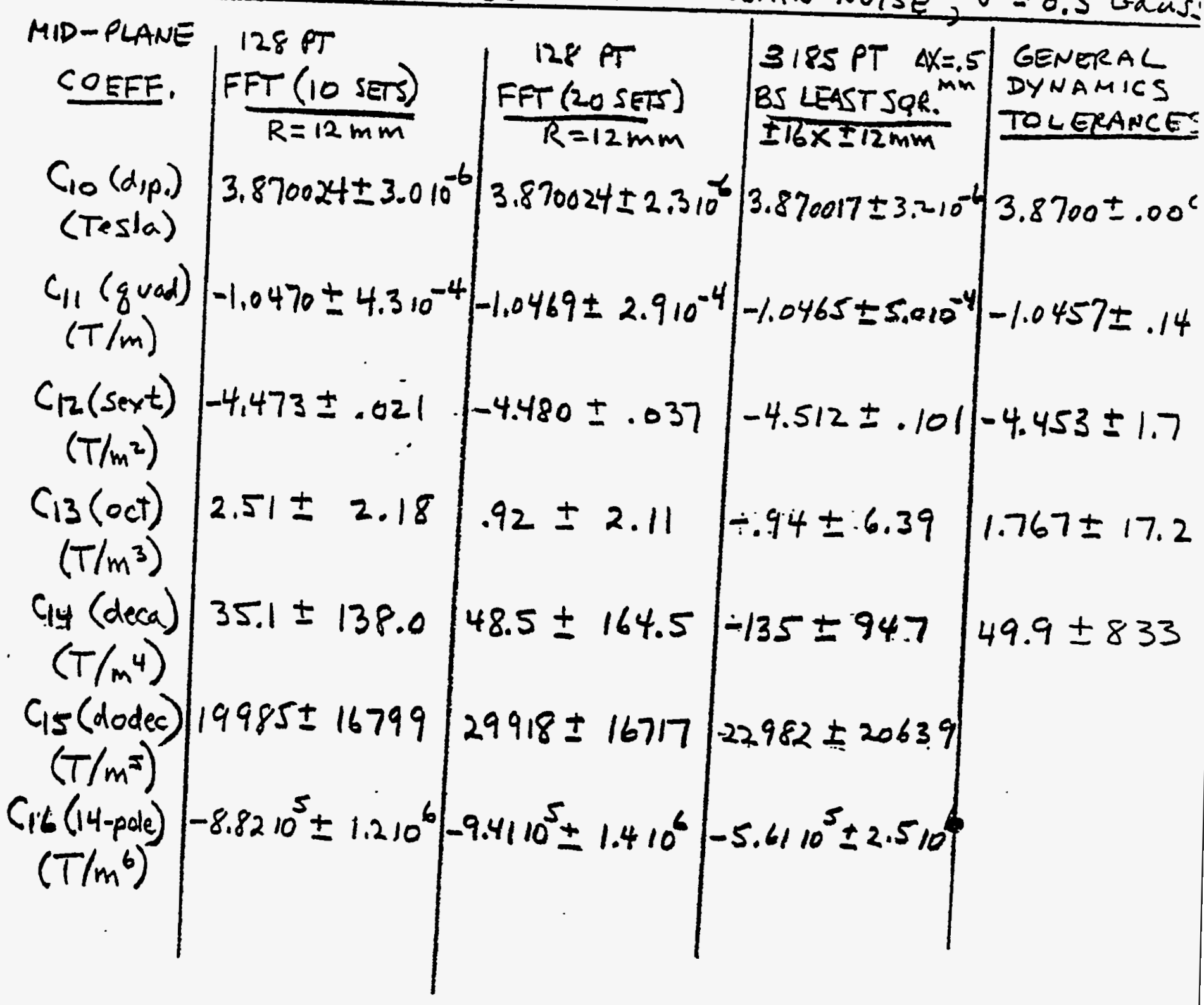

$-11-$ 


$$
\text { TABLE V } 8 / 28 / 91
$$

COMPARISON OF 128 POITT FFT FT T (10 DATA SESE) WITH LEAST SQUARES FIT of BROWN-SERURANCKX (BS) EXPANSION ON 4845 PoINT, $-21 \leq x \leq 21 \mathrm{~mm},-14 \leq z \leq 14 \mathrm{~mm} G R_{1 D}, \Delta x=0.5 \mathrm{~mm}$.

TOSCA DATA RANDOMIZED WITH $\sigma=0.5 G$ GAUSSIAN NOISE

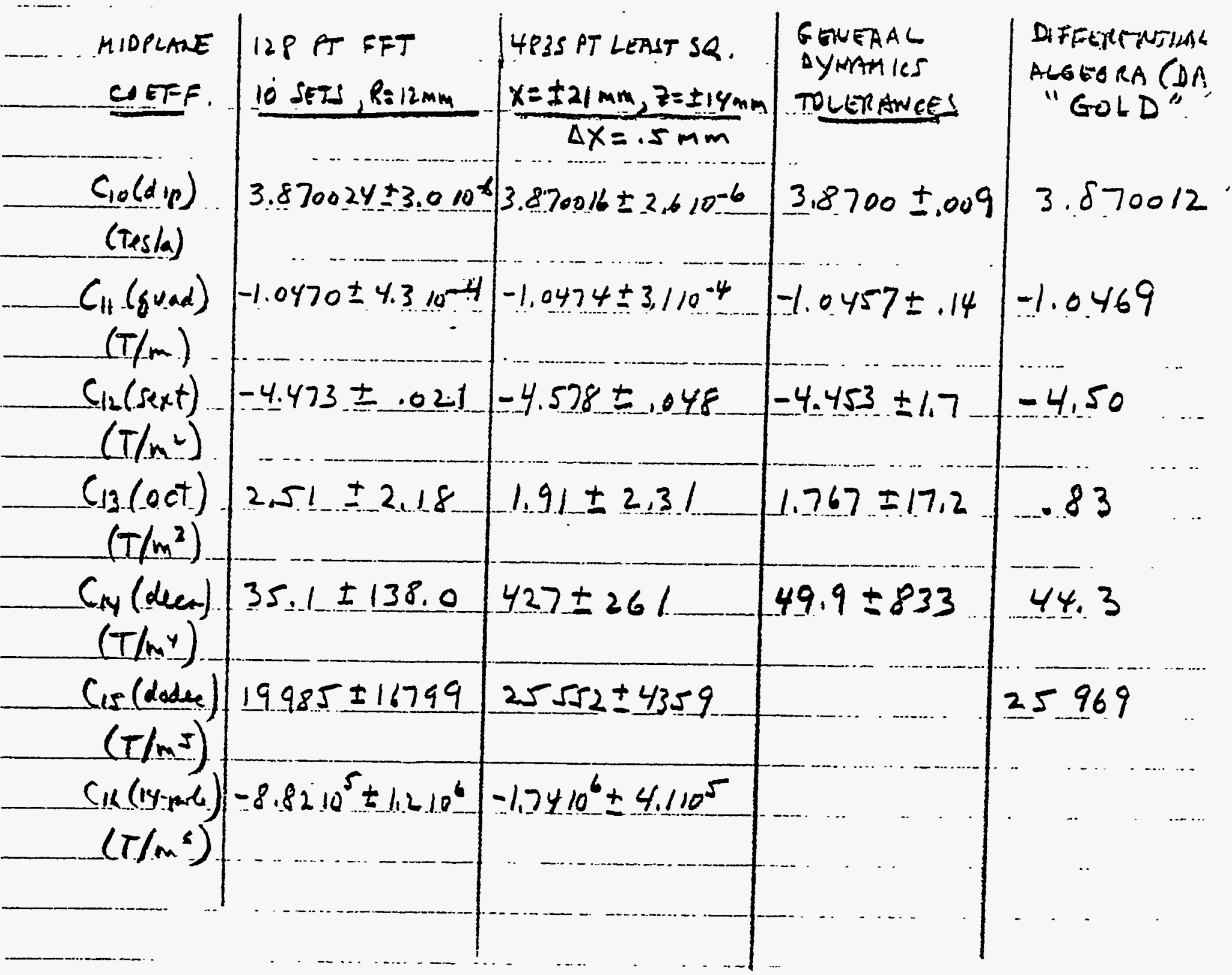

$-12-$ 
table Va

$8 / 4 / 91$

COIL NOV29

$\theta=90^{\circ}$

COMPAKISON OF MEOINU PLANE COEFINICIENTS FOR 128 point 10 -SET FFT AND BROWN-SERURENGIX LERST SQUAKES FIT TO 19097 points in $X= \pm 21 \mathrm{~mm} X Z= \pm 14 \mathrm{~mm}$ grid, $\Delta X=.25 \mathrm{~mm}$ GAUSSIAN NOISE witht $\sigma=0.5 \mathrm{G}$

6thorder

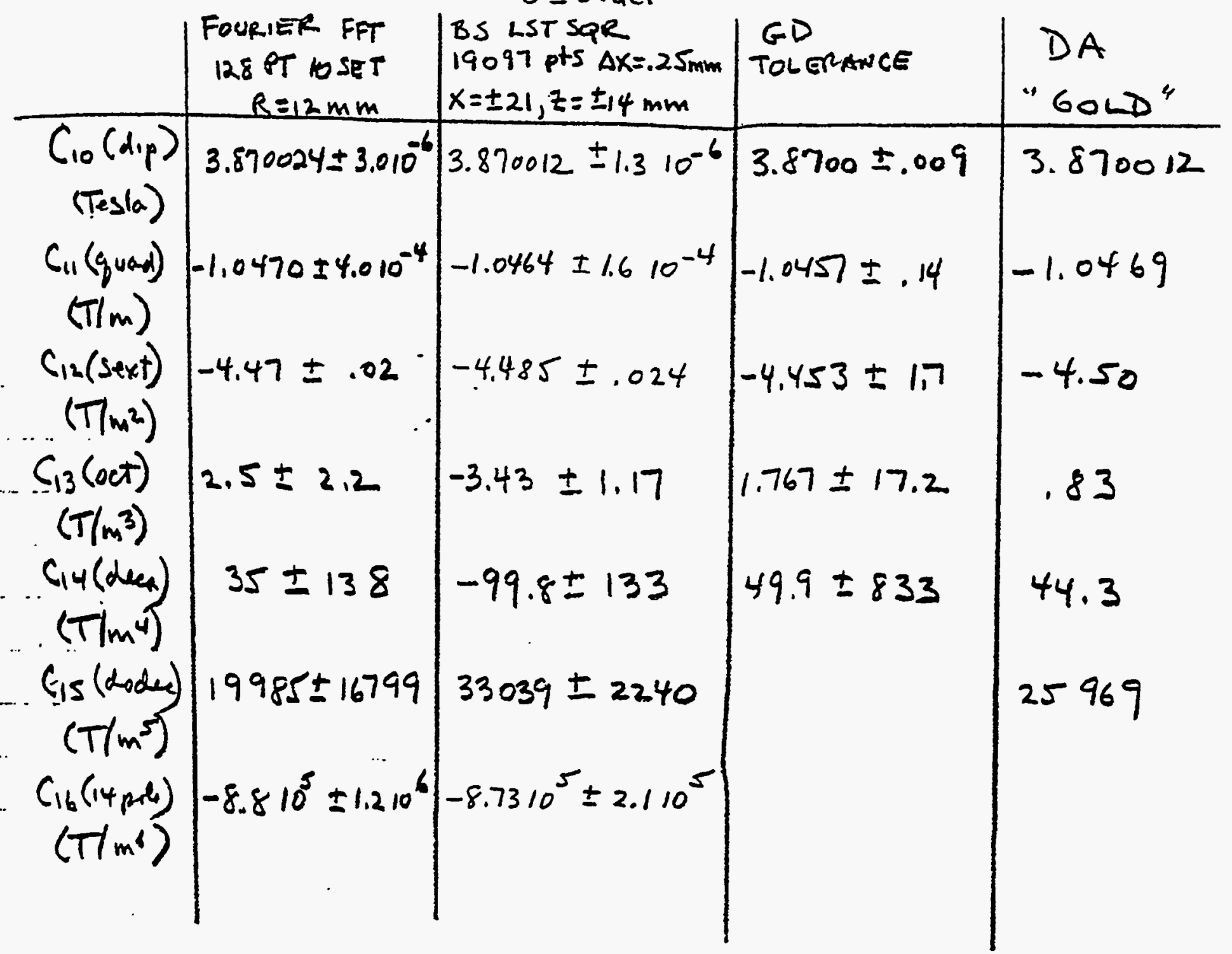

$-13-$ 


$$
\text { TABLE VI }
$$

$6 / 20 / 91 \operatorname{Roy} B$

$$
\phi=90^{\circ}
$$

COMPARISON OF FITS BY NILS LEAST SQUARES CODE TO NOV 29 $S \times L S$ COIL $Q=90^{\circ}$ TOSCA WII VARYING NUMBERS OF DATA POINTS iN INTERVAL $-30 \leq x \leq 30 \mathrm{~mm},-15 \leq Z \leq 15 \mathrm{~mm}$

$$
B_{z}=\sum_{m=0}^{N R / 2} \sum_{n=0}^{N R-2 m} C_{2 m+1, n} x^{n} y^{2 m}
$$

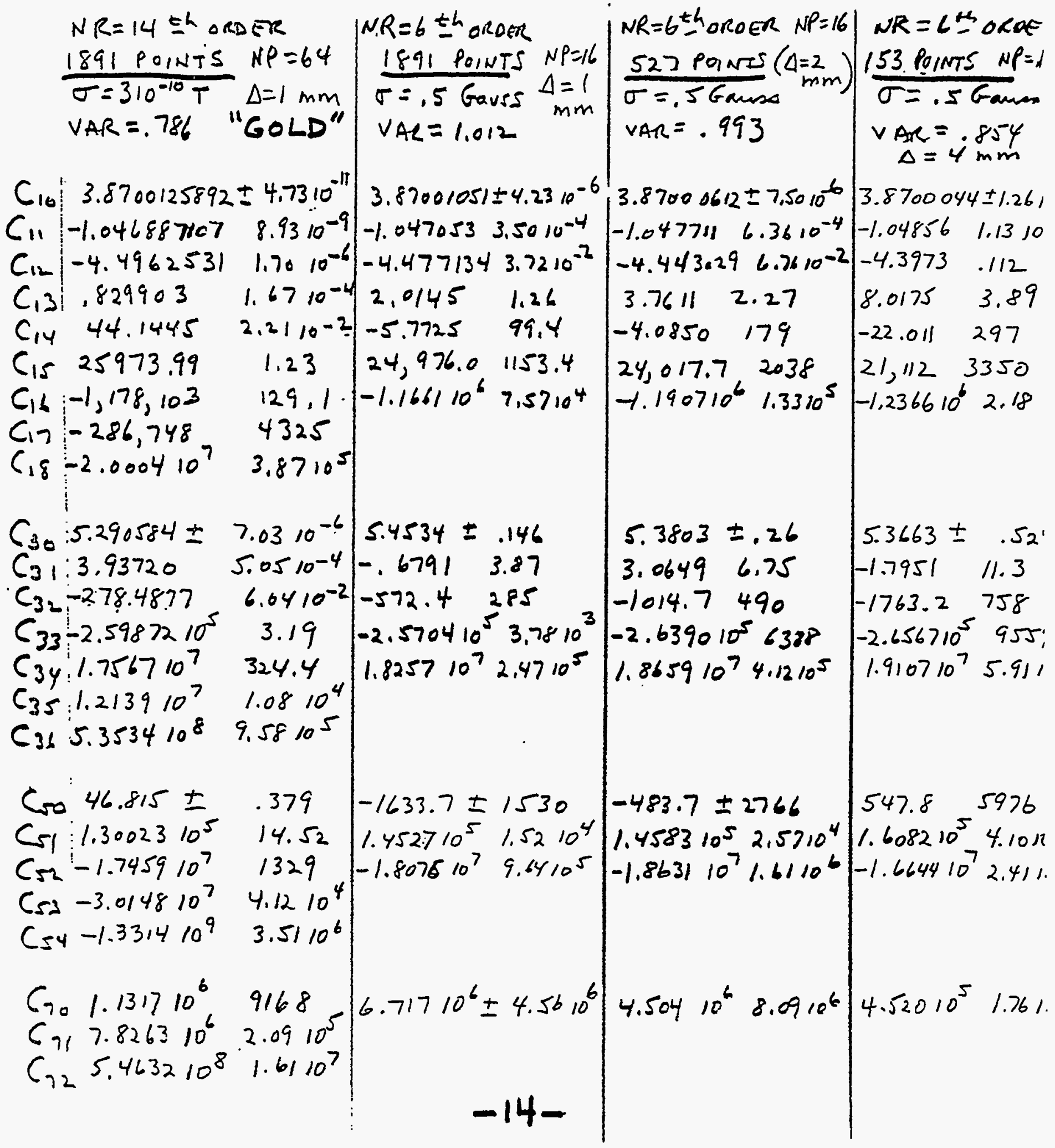


TABLE VII $8 / 16 / 91$

COMPARISON OF 128 PT EFT FIT( IO SETS) WITH LEAST SQUARES $F T$ OF BROWN-SERVRANKKX (BS) EXPANSION ON 7381 PT GRID, $-30 \mathrm{~mm} \leq X \leq 30 \mathrm{~mm},-15 \mathrm{~mm} \leq Z \leq 15 \mathrm{~mm}, D X=.5 \mathrm{~mm}$. TOSCA DATA RANDOMIZED with $\sigma=0,5$ GadS NOISE FROM GAUSSIAN. $\theta=90^{\circ}$, coillnovz

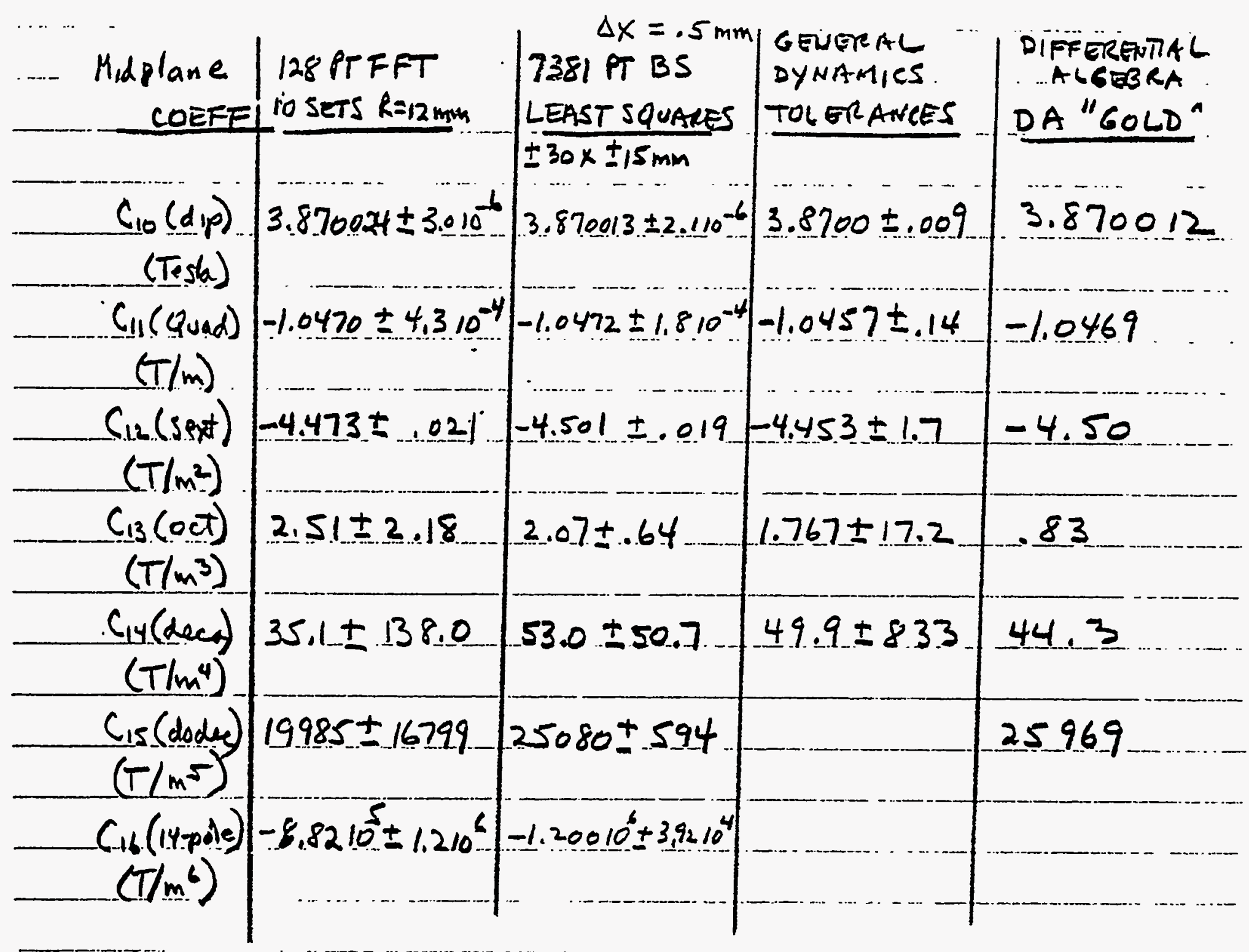

$-15-$ 


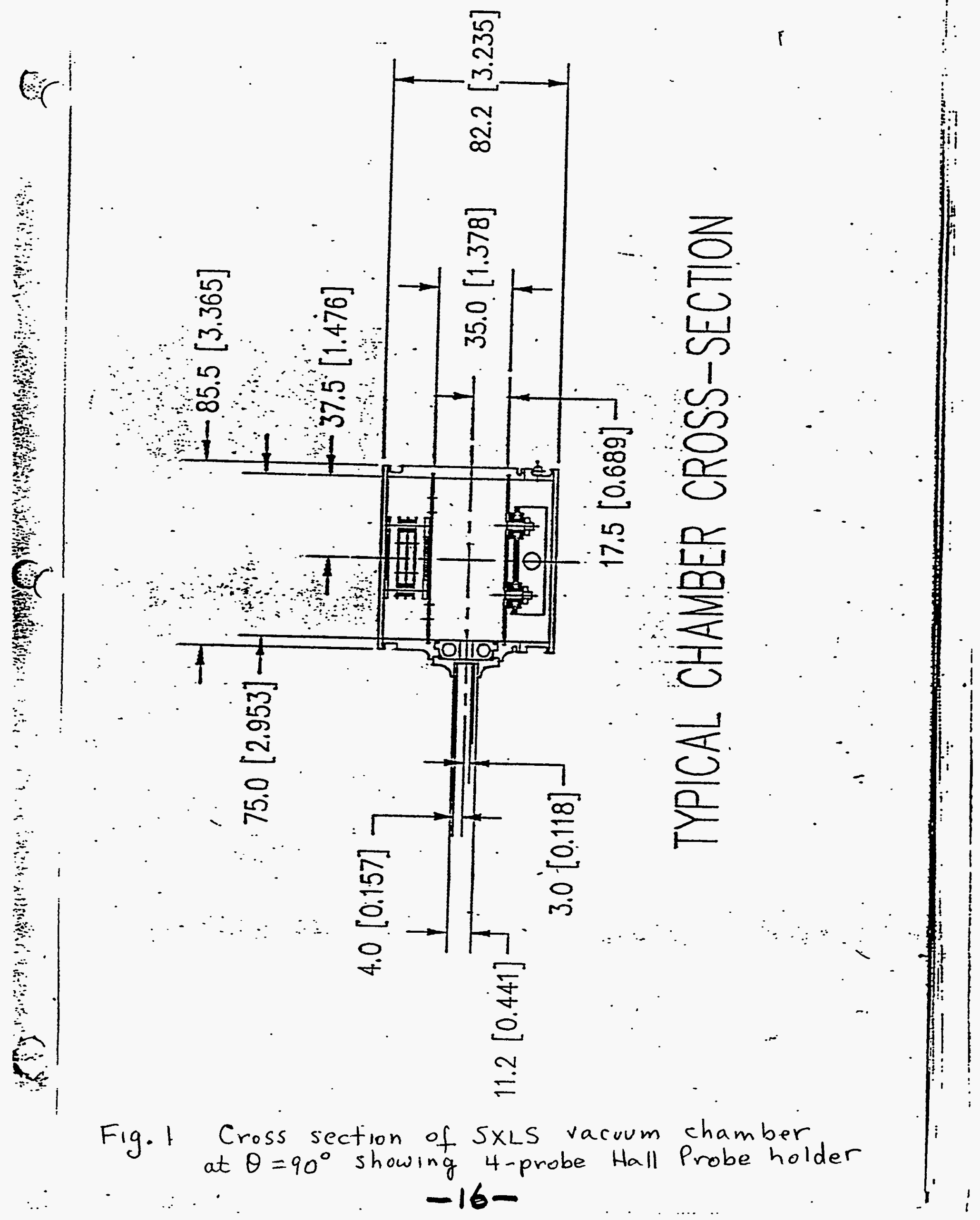




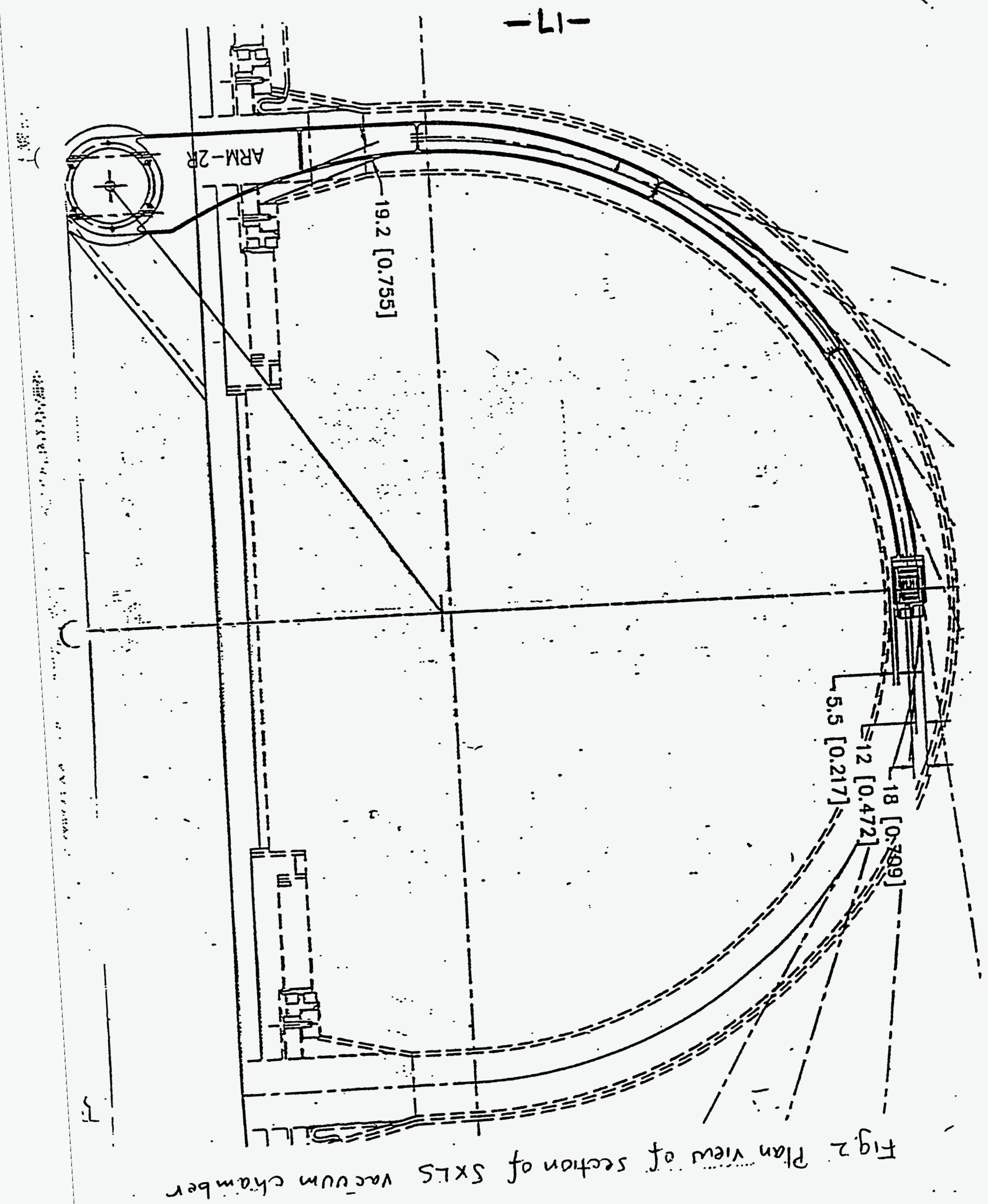




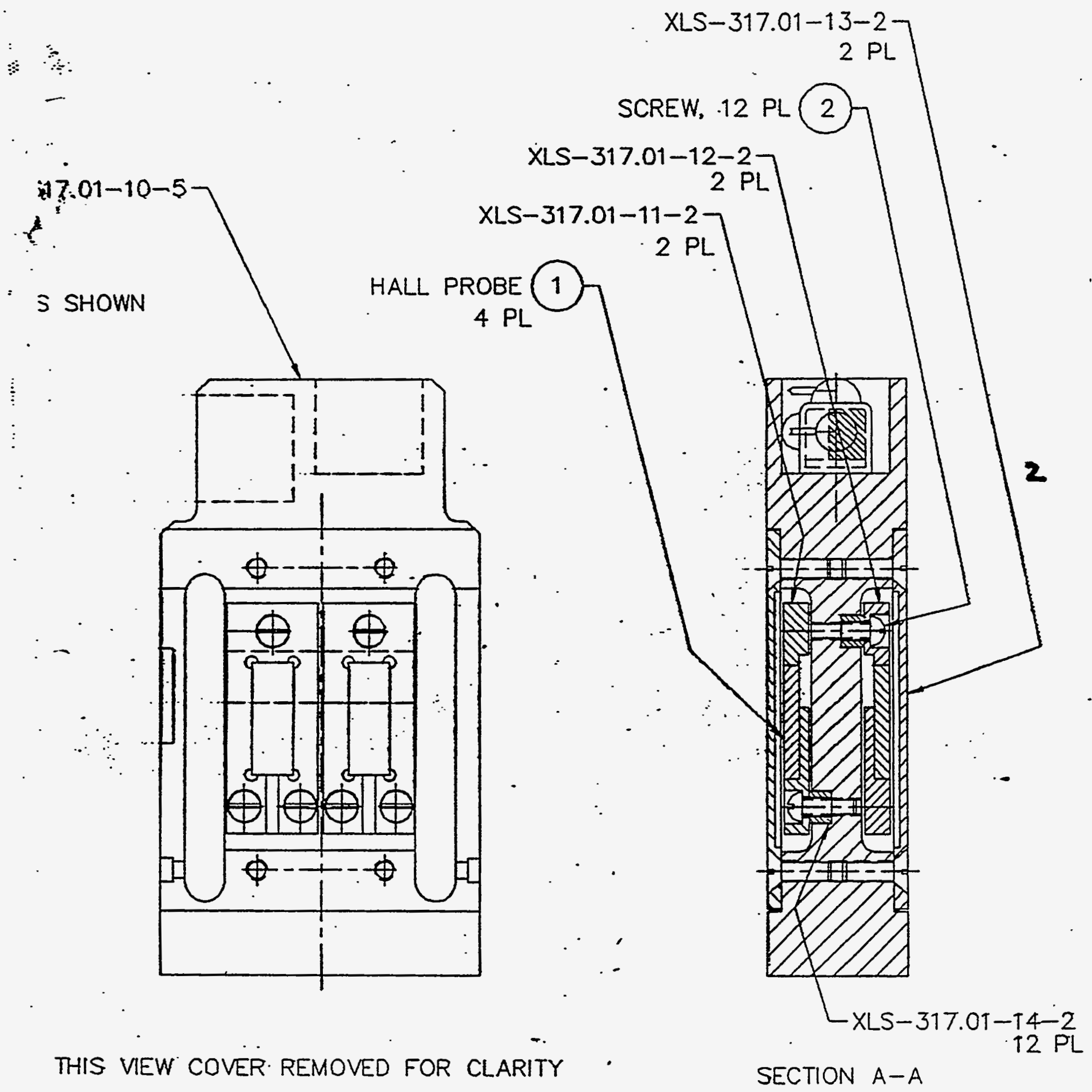

THIS VIEW COVER REMOVED FOR CLARITY • SECTION A-A

$\because$ Fig. 3 Detail of 4-probe Hall Probe holder for. magnetic measurements of SXLS magnet:

$$
-18-
$$


PROGRAM LSTSRRE

C GENERAL NONLINEAR LEAST SQUARES FITTING PROGRAM USING GALSS METHOD OF

C SUBROUTINE FIT TO FIT A FUNCTION $F(X ; P(1), \ldots P(N P))$. TO N DATA POINTS

C YD(1),..YD(N) AT ABSCISSAS $X(1), \ldots X(N)$ WHICH ARE READ IN BY LSTSQR OR,

C IF $N$ IS NEGATIVE, FROM FILE INDATA. WEIGHTS $W(1), \ldots W(N)$ ARE SUPPLIED

C BY SUBROUTINE PRELIM. FIT USES SUEROUTINE MATINV FOR MATRIX INVERSION

C AND SUBROUTINE CALC TO EVALUATE THE FUNCTION AND ITS DERIVATIVES WITH

C RESPECT TO THE NFP FREE PARAMETERS $P(1), \ldots$ P (NFP) WHERE NFP LE. NP. ANY

C COMBINATION OF THE NP PARAMETERS CAN BE HELD FIXED. PROGRAM COMPUTES

C GOODNESS OF FIT CHISQR=SUM(W(I)*(YC(I)-YD(I))**2) AND VARIANCE VAR=

C CHISQR/ (N-NFP). CCACONVERGENCE CRITERION AND NPR CONTROLS VARIOUS OUT

C PUT OPTIONS. SUBROUTINE POST IS CALLED AFTER FIT TO DETERMINE USER-

C CONTROLLED ACTION. FILENAMES OF INDATA AND OUTDATA ARE USER-SPECIFIED.

C 12/4/90 VAX VERSION: $F$ IS A FUNCTION OF IV INDEPENDENT VARIABLES, DATA

C ARRAY DIMENSIONS INCREASED TO 2000. THIS VERSION ASSUMES IV=2. SUBROU-

C TINE CALC EVALUATES 2-DIMENSIONAL MAGNETIC MULTIPOLE EXPANSION BY $=. .$.

C $1 / 6 / 91$ VERSION: NR AND NS ARE LIMITS OF DOUBLE SUMMATION FOR BY FROM

C BROWN AND SERVRANCKX.1/10/91: correctioris made for fixed parameters.

C $2 / 1 / 91$ version=REAL*16(n1156). 2/3/91=BS sum to order NR(n1157). 2/12/91

C VERSION (NLLSB) \& INCLUDE ODD-PARITY SERIES (SKEW) BY $=S U M(m=0, N S / 2)$ SUM ( $n=$

C $0, N S)(C(2 m+2, n) x * * n * y * *(2 m+1)\}$ where $C 20=P(N P R+1), \ldots C(N S+2)=P(N P) . N P=$

C NPR+NPS, NPR=(NR+2)**2/4, NPS $=(N S+2) * * 2 / 4 . N R=O R D E R$ OF REGULAR SERIES,

C NSmORDER OF SKEW SERIES. $7 / 3 / 91$ increased NPMAX to 260 , NMAX $=8000$.

IMPLICIT REAL*16(A-H, D-Z)

PARAMETER (IV=2)

DIMENSION $X(I V, 8000), Y D(8000), W(8000), Y C(8000), P(260), S(260)$,

1 DY (8000), PI (260), DP (260)

CHARACTER*10 DAY, HOUR:

CHARACTER* 12 INDATA, OUTDATA

CHARACTER*BO HEADER

CALL DATE (DAY)

CALL TIME (HOUR)

WRITE $(*, *)$ ' ENTER HEADER $(A B O)=$ '

READ (*, *) HEADER

10 WRITE (*, *) DAY," PROGRAM LSTSQR ENTER N, NR, NS, NP, NPR, CC='

READ (*,*) N, NR, NS, NP, NPR, CC

IF (N. EQ.O) STOP, USER-INITIATED PROGRAM TERMINATION'

IF (N.LT.O) GDTQ 20

WRITE $(*, *)$, ENTER YD (I), $X(1, I), X(2, I), \ldots I=1, N^{\prime}$

READ (*, *) (YD (I), I=1,N), $(\langle X(J, I), J=1, I V), I=1, N)$

WRITE $(*, *)$, ENTER PARAMETER GUESEES $P(I), I=1, N P=$,

READ (*, *) (P (I), I=1, NP)

GOTO 30

c

$20 N=-N$

$N$ is negative. Read data from an input file.

WRITE $(*, *)$, PLEASE ENTER NAME OF INPUT DATA FILE, INDATA='

READ (*,*) INDATA

QPEN ( 1, FILE=INDATA, STATUS=' OLD', FQRM=' FORMATTED')

$\operatorname{READ}(1,25)(Y D(I),(X(I, I), J=1, I V), I=1, N)$

25 FORMAT (3 (1PE17.9))

$\operatorname{READ}(1,26) \quad(P(I), I=1, N P)$

26 FDRMAT (1PE17. 10)

CLOSE (1)

30 CALL PRELIM $(N, X, Y D, P, N P, W)$

DO $35 I=1, N P$

$35 . P I(I)=P(I)$

40 CALL FIT (NR, NS, NP, P, N, X, YD, W, NPR, CC, VAR, YC, S, NC)

CALL POST ( $N, X, Y D, N P, P, N P R, N C, V A R, N T E S T$ )

IF (NTEST. EQ. 1) GOTO 40

C WRITE RESULTS ON OUTPUT FILE 
DO $50 I=1, N P$

$50 D P(I)=P I(I)-P(I)$

DQ $55 I=1, N$

$55 \mathrm{DY}(I)=Y D(I)-Y C(I)$

WRITE $(*, *)$, PLEASE ENTER NAME OF OUTPUT DATA FILE, OUTDATA='

READ $\{*, *)$ QUTDATA

OPEN (2, FILE=OUTDATA, STATUS=' NEW', FORM=' FORMATTED' )

WRITE (2, 57) DAY, HOUR, HEADER

57 FORMAT \& PROGRAM LSTSAR', ZA10,1\%, ABO)

WRITE (2, GO) VAR, NC

GO FORMAT ' PARAMETERS AND UNCERTAINTIES VAR=', 1PE10.4,' NC=', IZ/

$19 x$, 'FINAL PARAM', $8 x$, 'SIGMA $P$ INITIAL PARAM DELTA PARAM'/1)

WRITE $(2,70)(I, P(I), S(I), P I(I), D P(I), I=1, N P)$

70 FQRMAT (I3, 1PE17. 10,1PE15.7, 1PE15.7, 1PE15.7)

WRITE (2, 8O)

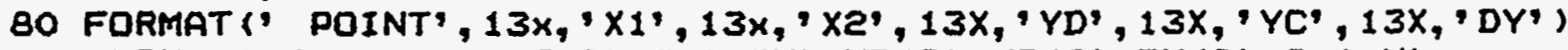

WRITE (2, 90) (I, $(X(J, I), J=1, I V), Y D(I), Y C(I), D Y(I), I=1, N)$

90 FORMAT (IE, SF 15.6)

CLDSE (2)

GOTO 10

END

SUBRQUTINE PRELIM IN, $X, Y D, P, N P, W)$

C TEST CASE FOR PROGRAM LSTSGR. READS CONSTANT WEIGHT WIN. $2 / 1 / 91=R E A L * 16$ IMPLICIT REAL*16(A-H, D-Z)

DIMENSION $X(2,8000), Y D(8000), P(260), W(8000)$

WRITE $(* ; *)$, PLEASE ENTER CONSTANT WEIGHT WIN='

READ (*,*) WIN

DO $10 \mathrm{~J}=1, N$

$10 W(J)=W I N$

RETURN

END

SUBRQUTINE FIT (NR, NS, NP, $P, N, X, Y D, W, N P R, C C, V A R, Y C ; S, N C$ )

C GENERAL NON-LINEAR LEAST SQUARES FIT BY GAUSS METHOD. SEE LOS

C ALAMOS REPORT LA-2367, MOORE AND ZEIGLER (1960). FITS FUNCTION

C $F(X ; P(1), \ldots P(N P))$ SPECIFIED BY SUBRQUTINE CALC TO N DATA PDINTS

C $(X(1), Y D(1)), \ldots(X(N), Y D(N))$. CALC ALSO EVALUATES DERIVATIVES DF

C F WITH RESPECT TO FREE PARAMETERS AND FUNCTION VALUE $Y C(I), I=1, N$.

C NPR=0,1,2 OR 3 GIVES NO LEVENEERG DAMPING. NPR=1 OR 4 GIVES A-MATRIX

C PRINT, NPR=2 OR 5 GIVES ITERATION PRINT, NPR=3 OR 6 GIVES CORRELATIDN

C MATRIX PRINT. ANY PARAMETER CAN BE FIXED IF NFIXP. GT. O, IN WHICH CASE

C PARAMETER NUMBERS. NFIX(I) WILL BE DELETED FROM P(I) TO GIVE ARRAY DF

C FREE PARAMETERS PF (I). CC IS CONVERGENCE CRITERION, VAR=CHISQR/NDF

C IS THE VARIANCE OF THE FIT, S(I) ARE THE UNCERTAINTIES IN THE FITTED

C PARAMETERS, AND NC IS THE NUMBER OF ITERATION CYCLES REQUIRED. 1Z/4/9O

C VAX VERSION: $F$ is a function of IV independent variables contained in

$C$ array $X(I V, N)$. This version uses IV=2 to evaluate $2-d i m e n s i o n a l$ mag-

c netic multipole data. NMAX=2000. 1/6/91 VERSION. NR AND NS ARE LIMITS

C OF BROWN AND SERURANCKX DOUBLE SUMATION FOR BY. USED IN CALC. $1 / 10 / 91$

C CORRECTIONS MADE FOR FIXED PARAMETER CASE. $2 / 1 / 91$ VEMSiOn=REAL*16.

C 2/12/91 VERSION:REGULAR \& SKEW SERIES TO NR-th AND NS-th ORDER, RESPEC

C TIVELY, NP= ( (NR+2)**2+(NS+2)**2)/4. NLLSB.7/3/91 NP to 260, N to BOOO.

IMPLICIT REAL*16(A-H, O-Z)

PARAMETER (IV=2)

DIMENSION P(260), $X(I V, 8000), Y D(8000), Y C(8000), W(8000), D F(260)$,

$1 V(260), D P(260), S(260), D I A G(260), R O W(260), A(33930), N F I X(260)$,

ᄅ PF (260), SF (260)

$\mathrm{DO} Z \mathrm{~J}=1, \mathrm{NP}$

2 $P F(J)=P(J)$

NFP $=N P$

WRITE $(*, *)$, NUMBER OF FIXED PARAMETERS NFIXP=" 
READ (*, *) NFIXP

IF (NFIXP.EQ. O) GOTO 7

IF (NFIXP. LT. O) GOTO 41

C NFIXP) O. Read in fixed parameter numbers NFIX(1), ....etc.

WRITE $(*, *)$, FIXED PARAMETERS NFIX $(J), J=1, N F I X P=$ ?

$\operatorname{READ}(*, *) \quad$ (NFIX (J), J $=1, N F I X P)$

EOTO 42

C NFIXP<O. There are fixed parameterg. Use existing values NFIX(I).

41 NFIXPE-NFIXP

42 NFP $\triangle N P-N F I X P$

$L=0$

DO $6 \mathrm{~J}=1$, NFIXP

$M=N F I X(J)$

DO $5 \mathrm{KaM}, \mathrm{NP}$

5 PF $(K-L)=P(K+1)$

$L=L+1$

6 CONTINUE

7 NA=NFP* $(N F P+1) / 2$

C

ENTER LOOP TO MODIFY FREE PARAMETERS PF (I).

DO $260 \quad I=1,70$

$N C=I$

CHISQR=0. ORO

DO $10 \mathrm{~J}=1$, NA

$10 A(J)=0.0 Q 0$

DO $20 \mathrm{~J}=1, N P$

$20 V(J)=0.0 Q 0$

LOOP TO FORM MATRIX A ÁND VECTOR V FOR N DATA POINTS.

DO $60 \mathrm{~K}=1, N$

CALL CALC (NR, NS, NP, $P, X(1, K), X(2, K), Y C(K), D F)$

IF (NFIXP. ER.O) GOTO 25

DO $22 J=1$, NP

Je $\operatorname{RON}(2)=D F(2)$

$L L=0$

DO $24 J=1$, NFIXP

$M=N F I X(J)$

DD 23 LmM, NP

23 DF $(L-L L)=R D W(L+1)$

$L L=L L+1$

24 CONTINUE

$25 D Y=Y D(K)-Y C(K)$

$L=1$.

DO $50 \mathrm{~J}=1$, NFP

IF (DF (J). NE. 0.OQO) GDTO 30

$L=L+N F P-J+1$

GOTO 50

$30 \mathrm{DO} 40 \mathrm{M}=\mathrm{J}, \mathrm{NFP}$

$A(L)=A(L)+D F(J) * D F(M) * W(K)$

$40 L=L+1$

$V(J)=V(J)+D F(J) * D Y * W(K)$

SO CONTINUE

60 CHISQR $=C H I S Q R+D Y * D Y * W(K)$

VAR=CHISQR/QFLOAT (N-NFP)

c

APPLY LEVENBERG DAMPING FACTOR FDL IF NPR.GT. 3

IF (NPR. LT. 4) GOTO 82

SUM $=0$. OQO

$J=1$

$L=1$

LLENFP

DO $70 \mathrm{~K}=1$, NFP

IF (A (L) . EQ. O. OQO) GOTO 310 
SUM $=S U M+V(J) * V(J) / A(L)$

$J=J+1$

$L=L+L L$

$70 L L=L L-1$

$F D L=1.0 Q O+2 . O Q O * S U M / C H I S Q R$

LII 1

LL=NFP

DO $80 \mathrm{~K}=1$, NFP

$A(L)=A(L) * F D L$

$L=L+L L$

$80 L L=L L-1$

C PRINT A-MATRIX IF NPR=1 OR 4

Q2 IF (NPR. NE. 1. AND. NPR. NE. 4) GOTO 100

IF (I. NE. 1) GOTO 90

WRITE $(*, *)$ ' MATRIX PRINT OF SUBROUTINE FIT'

90 WRI TE (*, 95) I, NFP, (A (K), $K=1, N A)$

95 FORMAT (" NC=', I2,' NFP=1, I $/(7(1 X, 1 P E 10.3))$ )

C

TEST FOR DIAGONAL ELEMENT OF A-MATRIX EQUAL ZERO.

$100 L=1$

LLONFP

DO $96 K=1$, NFP

IF (A (L) . EQ. 0. OQO) GOTO 310

$L=L+L L$

$96 L L=L L-1$

C

REPLACE A-MATRIX BY ITS INUERSE AND TEST IF SINGULAR.

CALL MATINV (A, NFP, NTEST)

IF (NTEST. NE. O) GQTO 280

C EVALUATE PARAMETER INCREMENTS DP(I) AND NEW PARAMETERS PF (I).

DQ $120 \mathrm{~K}=1$, NFP

$D P(K)=0.0 Q 0$

$L=K$

LL=NFP-1

DO $120 \mathrm{~J}=1$, NFP

$D P(K)=D P(K)+A(L) * V(J)$

IF (J.GE. K) GOTO 110

$L=L+L L$

$L L=L L-1$

GOTO 120

$110 L=L+1$

120 CONT INUE

DO $130 K=1$, NFP

$130 \mathrm{PF}(K)=P F(K)+D P(K)$

c

PRINT ITERATION RESULTS IF NPR=2 OR 5

IF (NPR. NE. 2. AND. NPR. NE. 5) GQTO 165

IF (I. NE. 1) GOTO 150

WRITE $(*, *)$ ' ITERATION PRINT OF SUBROUTINE FIT'

WRITE $(*, *)$, NC.

1

150 WRITE $(*, 160)$ I, (PF $(J), J=1,5)$, VAR

160 FORMAT $(1 X, I 2,1 X, 5(1 P E 12.5,1 X), 1$ PE10.4)

C FILL IN $P$ ARRAY WITH NEW PF VALUES AND TEST FOR CONUERGENCE.

165 IF (NF IXP.EQ. O) GOTO 166

$L=1$

DO $164 J=1$, NP

DO $162 K=1$, NFIXP

IF (NFIX (K). EQ.J) GOTO 164

162 CONT INUE

C PARAMETER J IS FREE PARAMETER. REPLACE IT WITH PF (L). $P(J)=P F(L)$

$L=L+1$ 
164 CONT INUE

GOTO 169

166 DO $167 \mathrm{~J}=1$, NP

$167 P(J)=P F(J)$

$16.9 \mathrm{DO} 170 \mathrm{~J}=1$, NFP

IF (PF (J).EQ. O. OQO) GOTT 170

IF (QABS (DP (J)/PF (J)) . GT.CC) GOTO 260

170 CONTINUE

C CALCULATION CONUERGED. COMPUTE PARAMETER UNCERTAINTIES $S$ (I)

175 CHISQR $=0.0$. OQO

DO $176 K=1, N$

CALL CALC (NR, NS, NP, $P, X(1, K), X(2, K), Y C(K), D F)$

$D Y=Y D(K)-Y C(K)$

176 CHISQR $=C H I S Q R+D Y * D Y * W(K)$

VAR $=C H I S Q R / Q F L O A T$ (N-NFP)

$L=1$

LL=NFP

DO $180 J=1$, NFP

$\operatorname{DIAG}(J)=A(L)$

SF (J) =QSQRT (QABS (DIAG ( $J$ *VAR) )

$L=L+L L$

$\because 180$ LL $=L L-1$

IF (NFIXP.EQ.O) EOTO 187

C FILL IN S ARRAY WITH NEW UNCERTAINTIES IF THERE ARE FIXED PARAMS $L=1$

DO $186 \mathrm{~J}=1$, NP

DO $182 K=1$, NFIXP

IF (NFIX (K). EQ. J) GOTO 184

182 CONTINUE

$S(J)=S F(L)$

$L=L+1$

GOTO 186

$184 S(J)=0.000$

186 CONTINUE

- GOTO 190

$187 D 018 B \quad J=1$, NP

$188 S(J)=S F(J)$

C

EUALUATE AND PRINT CORRELATION MATRIX IF NPR=3 OR 6.

190 IF (NPR. NE.3.AND. NPR. NE. 6) . GQTO 270

IF(I.NE. 1) GOTO 200

WRITE (*,*) ' CORRELATION MATRIX PRINT OF SUBROUTINE FIT'

200 DO $210 \mathrm{~J}=1$, NFP

$210 \operatorname{DIAG}(J)=1$. OQO/GSQRT (QABS (DIAG $(J))$ )

$L=1$

DO $250 \mathrm{~J}=1$, NFP

DQ $220 \mathrm{~K}=1, \mathrm{NFP}$

$220 \mathrm{ROW}(K)=0.0 Q 0$

DO $230 \mathrm{~K}=\mathrm{J}$, NFP

$R O W(K)=A(L) * D I A G(J) * D I A G(K)$

$230 L=L+1$

WRITE (*, 240) J, (ROW (K), $K=1, N F P)$

240 FQRMAT $(1 X, I 2,7(1 X, 1$ PE 10.3$))$

250 CONTINUE

GOTO 270

C

NO CONUERGENCE. CONTINUE ITERATIONS.

260 CONTINUE

270 RETURN

C

280 WRITE $(*, *)$ ' SUBROUTINE FIT ERROR IN MATRIX INUERSION' WRITE $\{*, 230) \quad N C,(A(M), M=1, N A)$ 


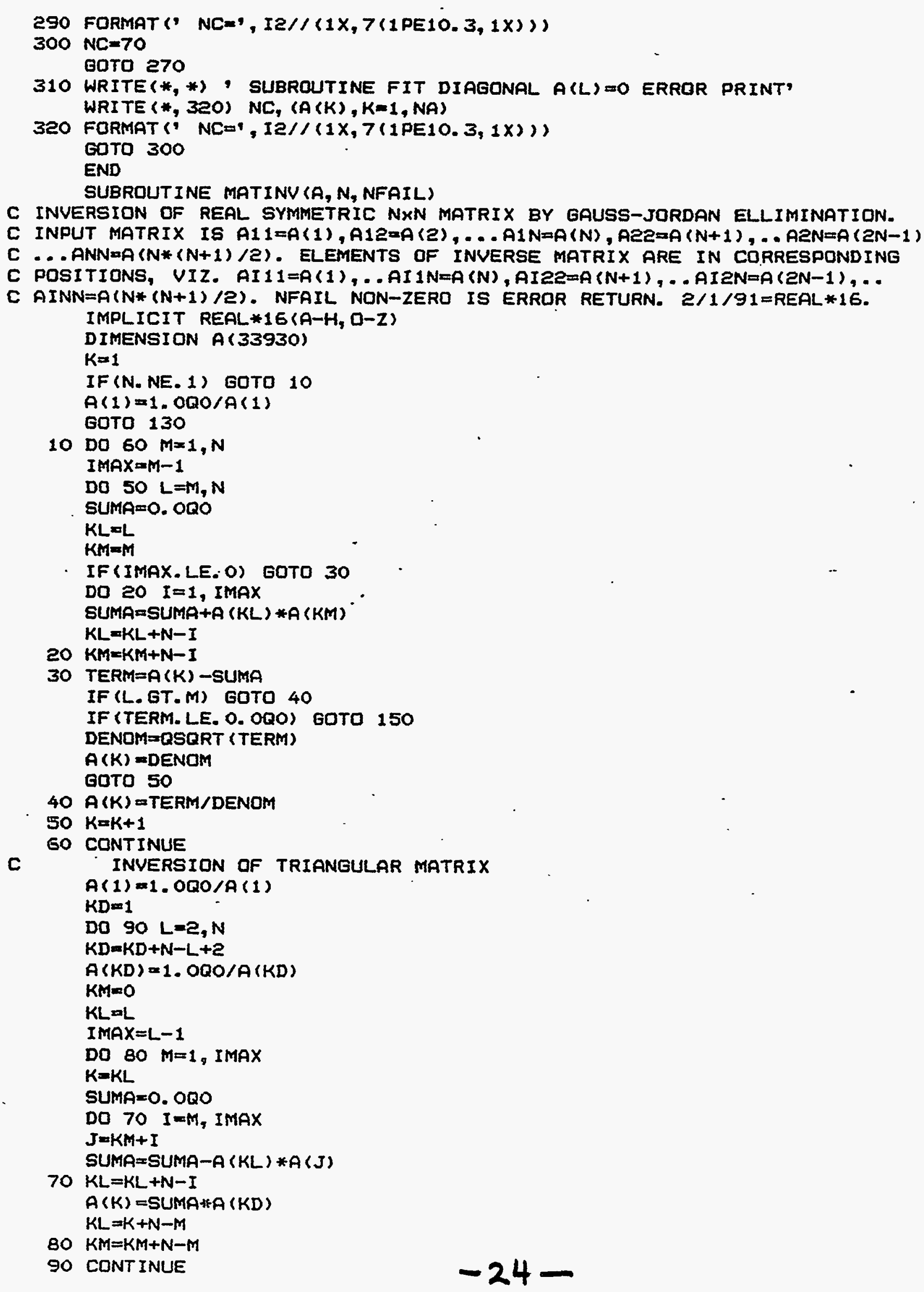


C

PREMLLTIPLY LOWER TRIANGLE BY TRANSPOSE

$K=1$

DO $120 \quad M=1, N$

$K L=K$

DO $110 \mathrm{~L}=\mathrm{M}, \mathrm{N}$

$K M=K$

IMAX $=N-L+1$

SUMA $=0 . O Q O$

DO $100 \quad I=1$, I MAX

SUMA $=5 U M A+A(K L) * A(K M)$

$K L=K L+1$

$100 K M=K M+1$

$A(K)=S U M A$

$110 \mathrm{~K}=\mathrm{K}+1$

120 CONTINUE

130 NFAIL $=0$

140 RETURN

150 NFAIL=K

GOTO 140

END

SUBROUT INE POST (ND, XD, YD, NP, P, NPR, NC, VAR, NTEST)

C TEST CASE FOR PROGRAM LSTSQR. IF FIT WAS SUCCESSFUL, DO NOTHING.

$\because$ C IF FIT DID NOT CONVERGE, OPTIONS ARE PROVIDED TO CHANGE INITIAL DATA,

C PARAMETERS, AND PRINTOUT MODE NPR OF SUBROUTINE FIT, OR JUST QUIT.

C 12/4/90 VAX VERSION: $F$ is-a function of IV independent variables in

C data array XD (IV,N). NMAX increased to 2000. $2 / 1 / 91$ version=REAL*16. IMPLICIT REAL*16(A-H, Q-Z)

PARAMETER (IV=2)

DIMENSION XD (IV, 8000), YD (8000), P(260)

CHARACTER* $1 Y$

CHARACTER*1 N

CHARACTER* 1 L

IF (NC. LT. 7O) EOTO 170

C . NCE7O. CALCULATION DID NOT CONVEREE. QUESTION USER.

WRITE (*; *)' FIT DID NOT CONUERGE. WANT TO TRY NEW FIT? (Y/N),

READ (*,*) L

IF (L.EQ.N) GOTO 190

USER WANTS TO TRY NEW FIT. WHAT CHANGES ARE DESIRED?

WRITE $(*, *)$ ' DO YOU WANT TO MODIFY OR ELLIMINATE DATA POINTS? (Y/N)' READ (*,*) L

IF (L. EQ.N) GOTO 70

C USER WANTS TO MODIFY DATA POINTS. READ NEW VALUES.

30 WRITE $(*, *)$, ENTER POINT NUMBER I AND NEW YD(I). I=O IS END, YD $(I)=$ 10 IS ELLIMINATE'

READ (*, *) I, YD (I)

IF (.I.EQ.O) GQTO 70

IF (YD(I).EQ. 0. OQO) GOTO 50

GOTO 30

C ELLIMINATE I-TH DATA POINT AND DECREMENT ND.

SO DO $60 \mathrm{~J}=1$, ND

$60 Y D(J)=Y D(J+1)$

ND $=N D-1$

GOTO 30

70 WRITE (*,*), DO YOU WANT TO MODIFY OR ELLIMINATE PARAMETERS? (Y/N)', $\operatorname{READ}(*, *) L$

IF (L.EQ.N) GOTO 130

C USER WANTS TO MODIFY OR ELLIMINATE PARAMETERS. READ NEW $P(I)$.

90 WRITE $(*, *)$, ENTER PARAM NUMBER I AND NEW $P(I) . I=0$ IS END, $P(I)=0 I S$ 1ELLIMINATE'

$\operatorname{READ}(*, *) I, P(I)$ 
IF(I.EQ. O) GOTO 130

IF (P (I). EQ. O. OQO) GQTO 110

EOTO 90

c

110 DO $120 \mathrm{~J}=1, \mathrm{NP}$

$120 \quad b(2)=P(J+1)$

NPENP-1

GOTD 90

130 WRITE $(*, *)$ " DO YOU WANT TO CHANGE FIT PRINTOUT WITH.NEW NPR? (Y/N), READ (*,*) L

IF (L. EQ.N) GOTO 160

c

USER WANTS NEW PRINTOUT FORMAT FROM SUBROUTINE FIT. READ NPR. WRITE $(*, *)$ ' PLEASE ENTER NEW PRINT NUMBER NPR='

160 NTEST $=1$ GOTO 200

170 WRITE (*, *) CALCULATION CONVERGED. PRINT RESULTS AND GOTO NEW CASE'

190 NTEST $=0$

200 RETURN

END

SUBROUTINE CALC (NR, NS, NP, P, $X 1, X 2, F, D F$ )

C CALCLLATES VERTICAL COMPONENT OF MAGNETIC FIELD BY=F FROM 2-DIMEN-

C SIONAL EXPANSION OF BROWN AND SERVRANCKX (SLAC-PUB-3381, JU1Y, 1984)

C By=SUM $(m=0, N R / 2)$ SUM $(n=0, N R) B(2 m+1, n) * X * * n * Y * * 2 m=B 10+(B 11 * X+\ldots B 1 N * X * N * N R)$

$C+Y * 2 *(B 30+B 31 * X+\ldots . .83 N * X * N N R-2)+Y * 4 *(B 50+B 51 * X+\ldots . . B 5 N * X * * N R-4)+\ldots$

$C+Y * * N R / 2 * B(N R+2,0) \cdot m=0,1, \dot{2}, \ldots$. NR/2. NR=even integer is specified order

$C$ of fit with $N P=(N R+2) * * 2 / 4.2 / 1 / 91$ version, REAL*16. (n1157). $2 / 12 / 91$

C version (NLLSs) a include odd-parity (skew) series By=SUM (m=0, NS/2) SUM ( $n=0$,

C NS) $B(2 m+2, n) x * * n * y * *(2 m+1 j$ where $B 20=P(N P R+1), C 21=P(N P R+2), \ldots C(N S+2,0)=$

$\because \quad C P(N P)$. NR=order of even-parity series, $N P R=(N R+2) * * 2 / 4$. NS=order of odd-

C parity series, NPS $=(N S+2) * * 2 / 4$. NP=NPR+NPS.

IMPLICIT REAL*16 (A-H, O-Z)

DIMENSION P(260), DF (260)

$F=0.0 Q 0$

$N P R=(N R+2) * * 2 / 4$

DO $10 \quad I=1$, NP

$10 \mathrm{DF}(I)=0.0 Q 0$

$K=N R+1$

$M=0$

C First, evaluate terms of even-parity series to NR-th order. $20 \mathrm{DO} 30 \mathrm{~N}=1, K$ $M R=M *(K+M+1)+N$

IF (X1.EQ. O. OQO) THEN

IF (X2. EQ. O. OQO) THEN

$\operatorname{DF}(1)=1.000$

$F=F+p(1)$

GOTO 50

ELSE

$D F(M R)=X 2 * *(2 * M)$

$F=F+P(M R) * D F(M R)$

GOTO 40

ENDIF

ELSE

IF $\{X 2$. EQ. O. OQO THEN

IF (M. GT. O) BOTO 50

$D F(M R)=X 1 * *(N-1)$

GOTO 30

ELSE

$D F(M R)=x 1 * *(N-1) * X 2 * *(2 * M)$

GOTO 30 


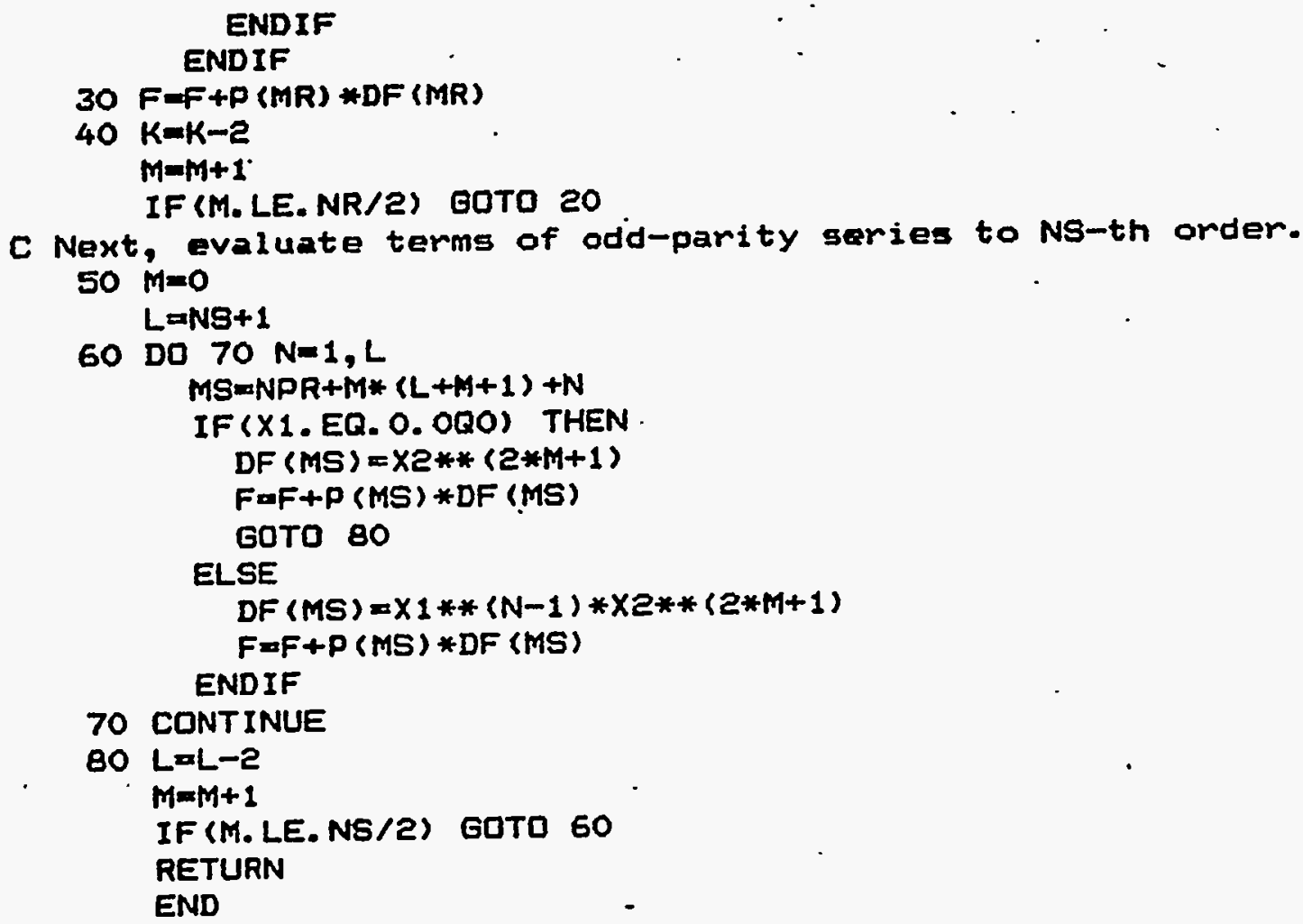


PROGRAM MULTIPOL

C Obtains the coefficients of the Mth order expansion $B=B O+B 1 * X t+B 2 *$

C $X t * * 2+B 3 * x t * * 3+\ldots . . . B m * x t * * m$ along a straight 1 ine perpendicular to

$C$ orbit at $N$ points $S 1, S 2, S 3, \ldots$.. Sn along the orbit by least squares fit

$C$ of multipole expansion in curvalinear coordinates to calculated values

$C$ of $B$ produced by TOSCA at $2 L+1$ points along the perpendicular. The

C orbit coordinates THETAi,Ri, $R^{\prime} i$ and $S i$ are obtained from file calcula-

$C$ ted by PROGRAM ORBIT. Also obtained is the integrated multipole streng

C ths and the tabulated multipole coefficients Bji at Si. The fit is per

C formed by subroutine LLSFIT. For NOPT 1 the coefficients are along

C actual orbit; for NOPT=e along the reference axis. A file of XT VS. BZ

$C$ is written in DIAGFILE for offline analysis by PROGRAM LLS if NDIAG)O.

C IF NDIAG $=-N, A$ 2-DIMENSIONAL ARRAY OF BZ VALUES WILL BE COMPUTED AT

C $(2 L+1) \times(L+1)$ POINTS ABOUT THE REFERENCE AXIS AT THETA=PI/2 AND WRITTEN

C TO GRIDFILE FOR SUBSEQUENT ANALYSIS. BY PROGRAM LSTSQR2. MOdifIEd $8 / 23 /$

C 91 to do vertical grid from $-K * D X$ to $+K * D X$.

IMPLICIT REAL*B (A-H, O-Z)

CHARACTER*10 HOUR, DAY

CHARACTER*12 ORBFILE, OUTFILE, DIAGFILE, GRIDFILE

CHARACTER*BO HEADER

PARAMETER (LMAX $=300$, $\operatorname{MMAX}=8, \mathrm{NMAX}=1001$ )

DIMENSION ORBDATA (7, NMAX), XT (LMAX), BZ (LMAX), SIGB (LMAX), P (MMAX),

1 COEFF (MMAX, NMAX), LP (MMAX), COVAR (MMAX, MMAX), SIGP (MMAX, NMAX),

2 SUM (MMAX), CHISQR (NMAX)

COMMON/PARAM/RIG, DEL, RO, YIN, YC

EXTERNAL FUNC

PIOVERZ=1.570796326795DO.

C Read control data

WRITE $(*, *)$, PLEASE ĖNTER HEADER (ABO) $=$ ?

READ $(*, *)$ HEADER

WRITE $(*, *)$, PLEASE ENTER $K, L, M, N, N O P T, N D I A G, D X, X I N, Y I N, Y C=$,

READ (*, *) K, L, $M, N, N D P T, N D I A G, D X, X I N, Y I N, Y C$

WRITE $(*, *)$, ENTER NAMES OF ORBFILE, OUTFILE, DIAGFILE, GRIDFILE='

READ (*,*) ORBFILE, OUTFILE, DIAGFILE, GRIDFILE

CALL TIME (HOUR)

CALL DATE (DAY)

OPEN (2, FILE=OUTF ILE, STATUS=' NEW', FORM=' FORMATTED')

WRI TE (2, 5) HEADER, DAY, HOUR, L, $M, N$, NOPT, NDIAG, DX, XIN, YIN, YC, OUTF ILE, 1 ORBFILE, DIAGFILE

5 FORMAT $(1 x, A 80$, , PROGRAM MULTIPOL', EA10/, L=', IZ, $M=9, I 1,1 N=1, I 3$,

1 ' NOPT=9, I1,' NDIAGa', I3,' DX=', F5. 3,' XIN=', F7.6,' YIN=1, F4. 3,

2 ' $Y C=1, F 6.4$,' OUTFILE=', $A 12, '$ DRBFILE=', $A 12$, , DFIL=', $P 12 / /$

3 , THETA (R) $S$ (METER) BO(TESLA). B1 $(T / m * * 1)$ BE (T/m**2) ',

4. B3(T/m*3) B4(T/m**4) BS(T/m**5) B6(T/m**G) B7(T/m**7),

5 ' CHISQR')

GOTO $(20,100)$ NOPT

C NOPT $=1$. Read in orbit data from ORBFILE.

20 OPEN (3, FILE=ORBFILE, STATUS=' OLD', FORM=' FORMATTED')

$\operatorname{READ}(3,30)(($ ORBDATA $(I, J), I=1,7), J=1, N)$

30 FORMAT $(7$ (F12. $9,1 x)$ )

CLOSE ( 3 )

C Main loop. Evaluate multipoles at $N$ positians $5 i$ or ORBDATA orbit. DT=ORBDATA $(1,2)$-ORBDATA $(1,1)$

40 CALL DATAIN(7)

DO $90 \quad I=1, N$

$C=D C O S(O R B D A T A(1, I))$

$S=D S I N(O R B D A T A(1, I))$

$X I=C * O R B D A T A(Z, I)$

$Y I=S * O R E D A T A\langle 2, I\rangle$

IF (DAES (ORBDATA $(1, I)$-PIOVER2).LE. 1. OD-10) GDTO 60 
RN=DRBDATA (3, I.) /ORBDATA (2, I)

$B=(-C * R N+S) /(S * R N+C)$

ALPHA=DATAN (B)

$C A=D C O S$ (ALPHA)

C

Evaluate $B Z$ vs. $X T$ at points Si using TOSCA.

\section{Do $50 \mathrm{~J}=-L, L$}

$L L \square J+L+1$

$X T(L L)=D F L Q T J(J) * D X$

$X D=X I+X T(L L) * C A$

$Y D=Y I+X T(L L) * C A * B$

$R=D S Q R T(X D * * 2+Y D * * 2)$

THETA $=D A C O S(X D / R)$

CALL ROY (R, THETA, O. ODO, BR, BT, BPERP)

$B Z(L L)=B P E R P$

50 SIGB $(L L)=1$. ODO

GOTO 70

C

$60 D Q 65 \mathrm{~J}=-\mathrm{L}, \mathrm{L}$

$L L=J+L+1$

$X T(L L)=D F L O T J(J) * D X$

$R=O R B D A T A(2, I)+X T(L L)$

CALL ROY (R, PIOVER2, O. ODO, BR, BT, BPERP)

$B Z(L L)=B P E R P$

65 SIGB (LL) $=1$. . ODO

C

Least squares fit of BZ vs. transverse position $X T$ to polyromial

$70 N D=2 * L+1$

$N P=M+1$

DO $75 \mathrm{~J}=1, \operatorname{MMAX}$

$75 L P(J)=J$

CALL LLSFIT (XT, BZ, SIGB, ND, P, NP, LP, NP, COVAR, MMAX, CHISG, FUNC)

CHISQR ( I ) $=$ CHISQ

DO $80 \mathrm{~J}=1$, NP

$\operatorname{SIGP}(L P(J), I)=D S Q R T(C Q V A R(L P(J), L P(J)))$

BO $\operatorname{COEFF}(J, I)=P(J)$

IF (NDIAG. NE. I) GQTO 90

OPEN (4, FILE=DIAGFILE, STATUS=' NEW', FORM=' FORMATTED')

WRITE $(4,85)$ (XT (J), BZ (J), $J=1, N D$ )

85 FORMAT (F8. 4, 1 $x, F 7.5$ )

CLOSE (4)

90 CONTINUE

C If $N D I A G=-N$ evaluate $B Z$ over a 2 -dimensional grid $(2 L+1) \times(L+1)$.

IF (NDIAG. EQ. -N. AND. NOPT. EQ. 2$)$ THEN

OPEN (5, FILE=GRIDFILE, STATUS=' NEW', FORM=' FORMATTED')

C $L E=L / 2$

DO $95 \quad I=-K, K$

$Z T=D F L Q T J(I) * D X$

DO $92 J=-L, L$

$L L=J+L+1$

$X T(L L)=D F L O T J(J) * D X$

$R=O R B D A T A(2, N)+X T(L L)$

CALL ROY (R, PIOVERZ, ZT, BR, BT, BPERP)

Э2 $\quad B Z(L L)=B P E R P$ WRITE (5, 94) (BZ (J), XT (J), ZT, J=1, ND)

94 FORMAT (3 (1PE17.9))

SE CONTINUE

CLOSE (S)

GOTO 200

ELSE

GOTO 200

END IF 
C NOPT=2. Evaluate multipolas along the reference axis starting

C.

C
$100 \mathrm{TI}=\mathrm{DATAN}(\mathrm{Y} I N / X I N)$
$D T=(P I Q V E R 2-T I) / D F L O T J(N-1)$
$T C=D A T A N(Y C / X I N)$

C Compute theta, $r, r$ and $s$ at $N$ positions. Store in DRBDATA array. $T=T I$

DO $110 J=1, N$

ORBDATA $(1, J)=T$

IF (DABS (T-PIQVERZ).LE. 1.OD-1O) THEN

ORBDATA $(Z, J)=Y C+X I N$

ORBDATA $(3, J)=0$. ODO

ORBDATA $(6, J)=Y C-Y I N+P I Q V E R E * X I N$

GOTO 110

ELSE

GOTO 105

$105 \quad C=D C O S(T)$

$S=D S I N(T)$

IF (T.LE. TC) THEN

DRBDATA $(2, J)=X I N / C$

ORBDATA $(3, J)=X I N * S / C * * 2$

DRBDATA $(6, J)=S *$ ORBDATA $(2, J)-Y I N$

ELSE

BETA=DASIN $(C * Y C / X I N)$

$T P=T-B E T A$

DRBDATA $(2, J)=D S Q R T(X I N * * Z+Y C * * Z+2$. ODO*XIN*YC*DSIN (TP) )

ORBDATA $(3, J)=X I N * Y C * D C O S(T P) / O R B D A T A(2, J) *(1.0 D O+Y C * S / X I N /$

1 DSRRT (1. ODO- (YC*C/XIN)**Z))

DRBDATA $(6, J)=Y C-Y I N+T P * X I N$

\section{ENDIF}

$110 \quad T=T+D T$

GOTO 40

C Integrate multipoles over $S$ with Simpsön's Rule. N=odd integer.

200 Do eeO $J=1$, NP

$\operatorname{SLM}(J)=0.000$

$\mathrm{DO} 210 \quad I=1, N$

IF $(J M O D(I, 2)$. EQ. O) CONST $=4.0 D O$

IF (JMOD $(I, 2)$. EQ. 1 ) CONST=2. ODO

IF (I.EQ.1.QRR. I.EQ.N) CONST $=1.000$

$210 \cdot \operatorname{SUM}(J)=\operatorname{SUM}(J)+\operatorname{CONST} * \operatorname{COEFF}(J, I) * D S Q R T($ ORBDATA $(2, I) * * 2+$

1 ORBDATA $(3, I) * * 2)$

2ह0 $\operatorname{SUM}(J)=\operatorname{SUM}(J) * D T / 3.0 D O$

c

Write coefficients to output file.

DO $305 J=1, N$

WRITE $(2,300)$ ORBDATA $(1, J), \operatorname{ORBDATA}(5, J),(\operatorname{COEFF}(I, J), I=1, M M A X)$,

1 CHISQR (J)

300 FORMAT (2(1x,FB. E), B(1x, 1PE12. 5), 1PE10. 3)

305 CONTINUE

WRITE (2, 310) (SUM(J), $J=1, N P$ )

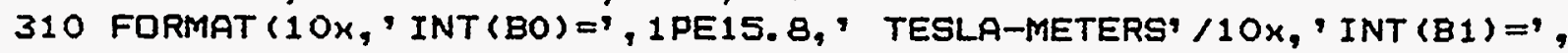

1 1PE15. 8," TESLA'/10X,'INT $(B 2)=", 1$ PE15. 8, " TESLA/METER'/10X,

2 'INT $(B 3)=$, , 1 PE 15.8,' TESLA/METER**2'/10x, 'INT (B4) =', 1 PE 15.8 ,

3 TESLA/METER**3'/10x, INT (BS) =', 1 PE15. 8,' TESLA/METER**4'/

$410 x, 9$ INT $(B 6)=9,1$ PE 15.8, , TESLA/METER**5, $/ 10 x, '$ INT (B7) =1, 1PE15. 8,

5 , TESLA/METER**6, )

CLDSE (Z)

CALL EXIT

END 
C $* * * * * * * * * * * * * * * * * * * * * * * * * * * * * * * * * * * * * * * * * * * * * * * * * * * * * * * * * * * * * * * * * * * * *$ SUBRQUTINE RQY (R, THETA, Z, ER, BTHETA, BZ)

C INPUTS: $R$, THETA and $Z$ in meters and radians, origin at machine center

C OUTPUTS: BR, BTHETA, BZ in Tesla

C REQUIRED FILE: corin.dat (Conductor description, in a form

C suitable for TOSCD, a collection of routines from ToSCA programs IMPLICIT REAL*B (A-H, Q

COMMON/PARAM/RIG, DEL, RO, YI, YC

C Convent to CENTIMETRES, and a coordinate system matching the one

C used in 〈conin. dat〉

$X X=\{R *$ dsin (THETA) -YC\} * 1.ODe

$Y Y=-R * d \cos (T H E T A) * 1 . O D E$

$Z Z=Z * 1.0 D E$

CALL SQURCE (XX, YY, ZZ, HXOUT, HYOUT, HZOUT)

c Compute RADIAL and AZIMUTHAL components

$B R=$ (HXQUT * dsin(THETA) - HYQUT * dcos (THETA) ) * 1. OD-4

BTHETA $=$ (HXOUT * dCOS (THETA) + HYOUT * dsin(THETA) ) * 1.OD-4

$\mathrm{BZ}=\mathrm{HZOUT} * 1 . \mathrm{OD}-4$

RETURN

END

C $* * * * * * * * * * * * * * * * * * * * * * * * * * * * * * * * * * * * * * * * * * * * * * * * * * * * * * * * * * * * * * * * * * * * * * 1$

SUBROUTINE LLSFIT $(X, Y, S I G, N D, A, M A, L I S T A, M F I T$, COVAR, NCM, CHISQ, FUNC)

C. Linear least squares from Press, et.21., "Numerical Recipes", P.513. Giver,

$C$ a set of ND points $X(I), Y(I)$ with individual standard deviations SIG(I

C use chi-square minimization to determine MFIT of MA coefficients $A$ of

$C$ a function that depends linearly on $A, y=s u m(A x A F U N C(x)$ ). The array

C LISTA renumbers the parameters so that the first MFIT elements corresp

C ond to the parameters actually being determined; the remaining MA-MFIT

$C$ elemerts are held fixed at their input values. The program returns val

C ues for the MA fit parameters $A, C H I S Q$, and the covariance matrix

C COVAR $(I, J)$. NCM is the physical dimension of COVAR(NCM, NCM) in the

C calling moutine. The user supplies a subrautine FUNC ( $X$, AFUNC, MA) that

$C$ returris the $M A$ basis furctions evaluated at $x=x$ in the array $A F U N C$. The

C program also uses subroutine GAUSSJ for matrix inversion by GAuss-Jord

$C$ an elliminatior. The variances $5 i g J 2$ of parameters $A(J)$ are the diag-

$c$ onal elements CJJ of COVAR.

IMPLICIT REAL*B (A-H, O-Z)

PARAMETER (NMAX $=50$ )

DIMENSION $X$ (ND), Y (ND), SIG (ND), A (MA), LISTA (MA), COVAR (NCM, NCM), 1 BETA (NMAX), AFUNC (NMAX).

C Check that LISTA contains proper permutation of coefficients and fill. $K K=M F I T+1$

DO $12 J=1$, MA

IHIT $=0$

DO $11 K=1$, MFIT

IF (LIETA (K). EQ. J) IHIT $=I H I T+1$

11 CONT INUE

IF (IHIT.EQ. O) THE'N

LISTA $(K K)=J$

$K K=K K+1$

ELSE IF(IHIT.GT. 1) THEN

STOP "Improper set in LISTA'

ENDIF

12 CONTINUE

IF (KK.NE. $(M A+1)$ ) STOP 'Improper set in LISTA'

C Initialize the symmetric matrix COVAR.

DO $14 J=1$, MFIT

DO $1 \Xi K=1$, MFIT

CQVAR $(J, K)=0$. ODO

$1 \Xi$ CONT INUE

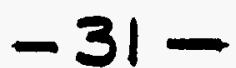




\section{CONT INUE}

C Loop over data to accumulate coefficients of the normal equations.

DQ $18 I=1, N D$

CALL FUNC $(X(I)$, AFUNC, MA)

$Y M=Y(I)$

IF (MFIT.LT.MA) THEN

C Subtract off dependences on known pieces of the fitting function. $D O 15 \mathrm{~J}=\mathrm{MFIT}+1, \mathrm{MA}$ $Y M=Y M-A(L I S T A(J)) * A F U N C(L I S T A(J))$

15 CONT INUE

\section{ENDIF}

SIGPI $=1.000 / S I G(I) * * 2$

DO $17 \mathrm{~J}=1$, MFIT

WT $=A F U N C$ (LISTA (J)) *SIGEI

DO $16 K=1, J$

$\operatorname{COVAR}(J, K)=\operatorname{COVAR}(J, K)+W T * A F U N C(L I S T A(K))$

16 CONTINUE

$$
\text { BETA }(J)=B E T A(J)+Y M * W T
$$

17 CONTINUE

18 CONTINUE

IF (MFIT.GT. 1) THEN

C Fill in above the diagonal from symmetry.

DO $21 \mathrm{~J}=2$, MFIT

$$
\text { DO } 19 K=1, J-1
$$

19

$\operatorname{COVAR}(K, J)=\operatorname{COVAR}(J, K)$

19ONT INUE

ENDIF

$$
\text { CONT INUE }
$$

\section{CONTINUE}

C Solve normal equations by matrix inversion method. CALL GAUSSJ (COVAR, MFIT, NCM, BETA, 1, 1)

DO $22 \mathrm{~J}=1$, MFIT

C Partial solution to appropriate coefficients $A$.

$A(L I S T A(J))=B E T A(J)$

2e CONTINUE

C Evaluate goodmess of fit CHISQ.

CHISQ=0. ODO

DO $24 I=1$, ND

CALL FUNC ( $X(I)$, AFUNC, MA)

SUM $=0$. ODO

DO $23 \mathrm{~J}=1, \mathrm{MA}$

SUM $=S U M+A(J) * A F U N C(J)$

\section{CONTINUE}

CHISQ $=C H I S Q+((Y(I)-S U M) / S I G(I)) * * 2$

\section{CONTINUE}

RETURN

END

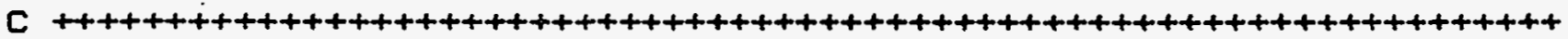

SUBROUTINE GAUSEJ (A, N, NP, B, M, MP)

C Linear equation solution by Gauss-Jordan ellimination from Press, et.

$C$ al., "Numerical Recipes", p. 28. $A$ is an input matrix of $N$ by $N$ elements

$C$ stored in an array of physical dimerisions NP by NP. $B$ is an input mat

$C$ rix of $N$ by $M$ containing the $M$ right hand side vectors stored in an

$C$ amray of NP by MP. On output $A$ is replaced by its matrix inverse and $B$

$C$ is replaced by the corresporiding set of solution vectors.

IMPLICIT REAL *B (A-H, O-Z)

PARAMETER (NMAX $=50$ )

DIMENSION A (NP, NP), E (NP, MP), IPIV (NMAX), INDXR (NMAX), INDXC (NMAX)

DO $11 \mathrm{~J}=1, N$

$\operatorname{IPIV}(J)=0$ 
11 CONT INUE

C Main loop over the columns to be reduced.

DO $22 \mathrm{I}=1, N$

$B I G=0.0 D O$

DO $13 \mathrm{~J}=1, \mathrm{~N}$

IF (IPIV (J).NE. 1) THEN

DO $12 K=1, N$

IF (IPIV $(K), E Q . O)$ THEN

IF (DABS $(A(J, K))$. GE. BIG) THEN

$B I G=\operatorname{DABS}(A(J, K))$

IROW $=3$

$I C O L=K$

ENDIF

ELSE IF (IPIV (K).GT. 1) THEN

STOP ' SINGULAR MATRIX'

ENDIF

12 CONTINUE

ENDIF

13 CONTINUE

IPIV (ICOL $)=I P I V(I C O L)+1$

C Interchange rows to put the pivot element on the diagonal.

IF (IROW. NE. ICOL) THEN

DO $14 L=1, N$

DUM=A (IROW, L)

- $A(I R O W, L)=A(I C O L, L)$

14 CONTINUE

DO $15 L=1, M$

DUM $\approx B(I R O W, L)$

$B(I R O W, L)=B(I C O L, L)$

$B(I C O L, L)=D U M$

15 CONTINUE

\section{ENDIF}

C Divide the pivot row by the pivot element located at IROW and ICOL. $\operatorname{INDXR}(I)=I R O W$

$I N D X C(I)=I C O L$

IF (ARICOL, ICOL) .EQ. O. ODO) STOP 'SINGULAR MATRIX' PIUINV $=1$. ODO $/ A$ (ICOL, ICQL)

$A(I C O L, I C O L)=1 . O D O$

Do. $16 L=1, N$

16 CONTINUE

DO $17 L=1, M$

$B(I C O L, L)=B(I C Q L, L) * P I V I N V$

17 CONT INUE

C Reduce the rows except for the pivot one.

DO $21 \quad L L=1, N$

IF (LL.NE. ICOL) THEN

DUM $=A$ (LL, ICOL)

$A(L L, I C D L)=0$. ODO

DO $18 L=1, N$
$A(L L, L)=A(L L, L)-A(I C O L, L) * D U M$

18 CONTINUE

DO $19 L=1, M$

$B(L L, L)=B(L L, L)-B(I C Q L, L) * D U M$

19 CONTINUE

ENDIF.

21 CONTINUE

Z2 CONTINUE

C Erid main loop. Intercharige pairs of columns in the reverse order. 
DO $24 L=N, 1,-1$

IF (INDXR (L), NE. INDXC(L)) THEN

DO $23 \mathrm{~K}=1, \mathrm{~N}$

DUM $=A(K, I N D X R(L))$

$A(K, \operatorname{INDXR}(L))=A(K, \operatorname{INDXC}(L))$

$A(K, I N D X C(L))=D U M$

23 CONTINUE

ENDIF

24 CONTINUE

RETURN

END

C

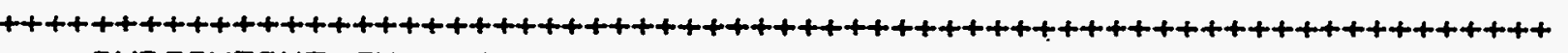

SUBROUTINE FUNC $(X, P, N P)$

C Fitting routine used by 1 inear least squares subroutine LLSFIT to

C evaluate a polynomial of degree NP-1 with NP adjustable coefficients

C $A(1), \ldots A(N P) . y(x)=a(1)+a(2) * x+a(3) * x * * 2+\ldots \ldots a(N P) * x * *(N P-1)$.

IMPLICIT REAL*8 (A-H, O-Z)

DIMENSION P(NP)

$P(1)=1.0 D O$

DO $11 J=2, N P$

$p(J)=p(J-1) * X$

11 CONTINUE

RETURN

END 


\section{PRDGRAM RANDBZER}

C Adds a random error of standard deviation SIGMA to mag field data BZ

C generated by TOSCADP in INFILE and writes modified data to OUTFILE.

C NSEED is an integer which starts the random generator RANGAUSS. The

$C$ data consists of NANGLES blocks of $B Z(X, Z)$ values with NROWS of $Z$-data

C arranged in NCOLS of X-values.

IMPLICIT REAL *B (A-H, O-Z)

REAL*4 R

CHARACTER*12 INFILE, DUTFILE

DIMENSION BZ (8000), X(8000), $Z(8000)$

WRITE $(*, *)$ 'Enter NANGLES, NROWS, NCOLS, NSEED, SIGMA='

READ (*, *) NANGLES, NROWS, NCOLS, NSEEED, SIGMA

WRITE $(*, *)$ ' Enter names of INFILE and QUTFILE='

READ (*,*) INFILE, QUTFILE

NLINES=NROWS*NCOLS

OPEN ( 1, FILE=INFILE, STATUS=' OLD', FORM=' FORMATTED')

OPEN (2, FILE=OUTFILE, STATUS=' NEW' , FORM=' FORMATTED')

C Loop to process data at each angle

DD $60 \quad I=1$, NANGLES

READ $(1,10)$ ANGLE

10 FORMAT ( $7 x, F 12.10)$

READ (1, 2O) (BZ (J), $X(J), Z(J), J=1, N L I N E S)$

2O FDRMAT (3 (1PE17.9))

DO $30 \mathrm{~J}=1$, NLINES

$R G=D B L E$ (RANGAUSS (NSEED))

$R=R A N D$ (NSEED)

IF (R. LE. 0.5) RG=-RE

$30 B Z(J)=B Z(J)+S I G M A * R G$.

WRITE $(2,40)$ ANGLE

40 FORMAT $(1 x$, ' THETA $=$ ', F12. 10)

WRITE $(2,20) \quad(B Z(J), X(J), Z(J), J=1, N L I N E S)$

60 CONTINUE

CLOSE (1)

CLOSE ( 2 )

CALL EXIT

END

FUNCTION RAND (NSEED)

C Generates random numbers from uniform distribution in interval

C O to 1. See "Oh! Pascal",D.Cooper \& M.Clancy, W.W.Norton \& Co.

C New York, 1982. P. 225. REAL*4 VAX version.

DATA MULT/25173/, INC/13849/, MODULUS/65536/, FMOD/65536. /

NSEED $=J M O D$ ( (MULT*NSEED+INC), MODULUS )

RAND =FLOAT $J$ (NSEED) $/ F M O D$

RETURN

END

FUNCTION RANGAUSS (NSEED)

C Generates random numbers from a normalized Gaussian distribution of

C rms width=1. The normalized probability function $S(X)$ is the integral

C (o to $X) P(T) D T$ where $P(T)=2 /$ sqrt $(2 * p i) * \exp (-T * 2 * 2 / 2)$. REAL*4 VAX version

$C$ Random numbers are in interval 0 to 3.9. Use is made of random gener-

C ator from uriform distribution in interval 0 to 1 from "Oh! Pascal",

C D. Cooper \& M.Clancy,W.W. Norton \& Co. (NY, 1982) P. Zes.

DIMENSION $x(128), 5(128)$

DATA $X / 0 ., .02, .04, .06, .08, .1, .12, .14, .16, .18, .2, .22, .24, .26, .28$, $1.3, .32, .34, .36, .38, .4, .42, .44, .46, .48, .5, .52, .54, .56, .58, .6, .62$,

$2.64, .66, .68, .7, .72, .74, .76, .78, .8, .82, .84, .86, .88, .9, .92, .94, .96$,

$3.98,1 ., 1.02,1.04,1.06,1.08,1.1,1.12,1.14,1.16,1.18,1.2,1.22,1.24$,

$41.26,1.28,1.3,1.32,1.34,1.36,1.38,1.4,1.42,1.44,1.46,1.48,1.5$,

$51.52,1.54,1.56,1.58,1.6,1.62,1.64,1.66,1.68,1.7,1.72,1.74,1.76$,

6 1. $78,1.8,1.82,1.84,1.86,1.88,1.9,1.92,1.94,1.96,1.98,2$. , 2. $05,2.1$, 
7 2. 15, 2. 2, 2. 25, 2. 3, 2. 35, 2. 4, 2. 45, 2. 5, 2. 55, 2. 6, 2. 65, 2. 7, 2. 75, 2. 8,

8 2. $85,2.9,2.95,3 ., 3.1,3.2,3.3,3.4,3.5,3.7,3.9 /$

DATA $5 / 0 ., .016, .032, .0478, .0638, .0796, .0956, .1114, .1272, .1428$,

1 . 1586, . 1742, . 1896, . 2052, . 2206, . 2358, . 251, . 2662, . 2812, . 296, . 3108,

2. $3256, .34, .3544, .3688, .383$, . 397, . 4108, . 4246, . 438, . 451 4, . 4648,

$3.4778, .4908, .5034, .516, .5284$, . 5408, : 5528, . 5646, . 5762, . 5878, . 599,

$4.6102, .6212, .6318, .6424, .6528, .663, .673, .6826, .6922, .7016, .7108$,

5 . 7198, . 7286, . 7372, . 7458, . 754, . 762, . 7698, . 7776, . 785, . 7924, . 7994,

$6.8064, .8132, .8198, .8262, .8324, .8384, .8444, .8502, .8558, .8612$,

$7.8664, .8714, .8764, .8812, .8858, .8904, .8948, .899, .903, .907, .9108$,

8.9146,.9182,. 9216,. 925, . 9282, .9312,. 9342, . 9372,. 9398, .9426, . 9452,

$9.9476, .95, .9522, .9544, .9596, .9642, .9684, .9722, .9756, .9786, .9812$,

$1.9836, .9858, .9876, .9892, .9906, .992, .993, .994, .9948, .9956, .9962$,

2.9968, . 9974,. .998, .9986, .999, . 9994, .9996, . 9998, 1. I

DATA MULT/25173/, INC/13849/, MODLLUS/65536/,FMOD/65536. /

NSEED = JMOD ( (MULT *NSEED+INC), MODULUS)

R=FLOATJ (NSEED) /FMOD

DO $10 I=2,128$

IF (R.LE. $S(I)$ ) THEN

RANGAUSS $=X(I)-(S(I)-R) *(X(I)-X(I-1)) /(S(I)-S(I-1))$

GOTO 20

ENDIF

10 CONTINUE

RANGAUSS $=x(128)$

20 RETURN

END 